\title{
Mitochondrial Translation and Beyond: Processes Implicated in Combined Oxidative Phosphorylation Deficiencies
}

\author{
Paulien Smits, Jan Smeitink, and Lambert van den Heuvel \\ Department of Pediatrics, Nijmegen Center for Mitochondrial Disorders, Radboud University Nijmegen Medical Center, \\ Geert Grooteplein 10, P.O. Box 9101, 6500 HB Nijmegen, The Netherlands \\ Correspondence should be addressed to Lambert van den Heuvel, b.vandenheuvel@cukz.umcn.nl
}

Received 31 October 2009; Accepted 29 January 2010

Academic Editor: Aikaterini Kontrogianni-Konstantopoulos

Copyright ( $(2010$ Paulien Smits et al. This is an open access article distributed under the Creative Commons Attribution License, which permits unrestricted use, distribution, and reproduction in any medium, provided the original work is properly cited.

Mitochondrial disorders are a heterogeneous group of often multisystemic and early fatal diseases, which are amongst the most common inherited human diseases. These disorders are caused by defects in the oxidative phosphorylation (OXPHOS) system, which comprises five multisubunit enzyme complexes encoded by both the nuclear and the mitochondrial genomes. Due to the multitude of proteins and intricacy of the processes required for a properly functioning OXPHOS system, identifying the genetic defect that underlies an OXPHOS deficiency is not an easy task, especially in the case of combined OXPHOS defects. In the present communication we give an extensive overview of the proteins and processes (in)directly involved in mitochondrial translation and the biogenesis of the OXPHOS system and their roles in combined OXPHOS deficiencies. This knowledge is important for further research into the genetic causes, with the ultimate goal to effectively prevent and cure these complex and often devastating disorders.

\section{Introduction}

Mitochondria are essential organelles that are present in virtually all eukaryotic cells. They originated from an ancestral alpha-proteobacterial endosymbiont [1]. The primary function of the mitochondrion is ATP production via the oxidative phosphorylation (OXPHOS) pathway. Additionally, mitochondria have been found to perform crucial roles in many other metabolic, regulatory and developmental processes. Mitochondrial dysfunction can therefore result in a variety of diseases, including common multifactorial disorders such as diabetes [2, 3] and Parkinson's disease [4]. Furthermore, mitochondria are implicated in the normal aging process $[5,6]$. The term mitochondrial disorder usually refers to diseases that are caused by disturbances in the OXPHOS system. This is a heterogeneous group of often multi-systemic and early fatal diseases, which are amongst the most common inherited human diseases [7].

The OXPHOS system is embedded in the mitochondrial inner membrane and consists of five multiprotein enzyme complexes (I-V) and two electron carriers [8]. The main function of the system is the coordinated transport of electrons and protons, resulting in the production of ATP. The great complexity of the OXPHOS system, which comprises almost 90 proteins encoded by both the nuclear and the mitochondrial genomes, explains the heterogeneity in clinical phenotypes that are associated with genetic defects in oxidative phosphorylation. Approximately 67\% of the OXPHOS disorders diagnosed at our centre consist of isolated enzyme deficiencies, whereas in 33\% of the cases multiple enzyme complexes show lowered activities [9]. Due to the dual genetic control, the defect can be located on the nuclear $(\mathrm{n})$ as well as the mitochondrial (mt) DNA. Isolated OXPHOS deficiencies are generally caused by mutations in structural genes (encoding subunits of the OXPHOS system) or in genes encoding proteins involved in the assembly of a specific OXPHOS enzyme complex $[10,11]$. For combined deficiencies the situation is more complicated. Most mutations associated with combined OXPHOS defects have been reported in mtDNA-encoded transfer (t) and ribosomal (r) RNAs [12]. Additionally, nDNA-encoded proteins required for the replication and integrity of mtDNA, such as polymerase $\gamma$ and thymidine kinase, are implicated in combined deficiencies [13]. 
Recently, mutations in nine different nuclear gene products involved in mitochondrial protein synthesis were reported: elongation factors mtEFG1, mtEFTs and $\mathrm{mtEFTu}$, small ribosomal subunit proteins MRPS16 and MRPS22, aspartyl- and arginyl-tRNA synthetases, and tRNA-modifying enzymes PUS1 and TRMU [14-25]. These findings defined a new class of gene defects underlying combined OXPHOS disorders. In general, when multiple OXPHOS enzymes are affected, the genetic defect is presumed not to be located in genes encoding OXPHOS subunits, but rather in genes needed for mtDNA maintenance, mitochondrial transcription or translation including posttranscriptional or -translational processes, import of nDNA-encoded proteins into the mitochondrion or mitochondrial membrane biogenesis. Given the number of proteins involved in these processes, a comprehensive overview of the processes and proteins that could be implicated in combined OXPHOS deficiencies is important for further research into the cause of these complex diseases.

This review will focus on the mammalian mitochondrial translation and its role in mitochondrial disorders. However, other processes implicated in combined OXPHOS deficiencies, in particular combined OXPHOS deficiencies with normal complex II activities, and indirectly related to mitochondrial translation will also be outlined. We will first describe which processes are required before protein synthesis can take place in the mammalian mitochondrion and which components are needed for these processes. Second, the current state of knowledge of the mitochondrial translation machinery and the mechanism of translation, including regulation and functions of translation factors beyond protein synthesis, will be discussed. Third, we will cover posttranslational processes with a functional OXPHOS system as end result. Fourth, we will give a non-exhaustive overview of the mutations that have been reported to impair mitochondrial protein synthesis and result in OXPHOS deficiencies. And finally, prospects of research into the pathogenesis of mitochondrial disorders will be mentioned.

\section{Requirements before Mitochondrial Translation Can Take Place}

For translation in the mitochondrion to be able to take place, a number of conditions have to be fulfilled. First of all, mtDNA has to be present, maintained, replicated and transcribed. Additionally, nuclear-encoded proteins required for the proper functioning of the mitochondrion have to be imported from the cell cytoplasm. These processes will now be discussed successively. Figure 1 gives an overview of the major processes (in)directly involved in the biogenesis of the OXPHOS system and covered in this review.

2.1. Human mtDNA. The mitochondrial genome is a double-stranded, circular molecule of 16659 base pairs. It is a highly compact genome that lacks introns and contains only one major non-coding region (the displacement or Dloop) and 37 genes, which code for 22 tRNAs, 2 rRNAs and 13 polypeptide subunits of the OXPHOS complexes I, III,
IV and V [26]. These genes are located on both strands of the mtDNA molecule, the heavy $(\mathrm{H})$ and light $(\mathrm{L})$ strand. MtDNA has a mutation rate 10-20 times that of nDNA [2729], which is thought to be caused by the lack of protective histones, slightly limited DNA repair and proximity to damaging reactive oxygen species (ROS) generated at the inner membrane. The unique features of mitochondrial genetics are essential for understanding the etiology and pathogenesis of mitochondrial disorders [30]: (a) mtDNA is maternally inherited; (b) cells typically contain hundreds of mitochondria and thousands of mtDNA molecules (polyplasmy); (c) mutations can affect all mtDNA copies in an individual (homoplasmy) or only some copies resulting in the coexistence of two or more mtDNA genotypes within a single cell, organ or individual (heteroplasmy); (d) in case of heteroplasmy, a minimum percentage of mutated mtDNAs has to be present in a cell for the OXPHOS system to malfunction (threshold effect) and this threshold level varies widely between different tissues; (e) during mitosis both normal and mutant mtDNA are randomly distributed to the daughter cells, which can result in changing mutational loads during the life of the patient and different mutational loads in different cells and tissues (mitotic segregation).

2.2. Maintenance and Replication of mtDNA. Unlike nDNA, which replicates only once during cell division, mtDNA is continuously replicated, independent of the cell cycle and also in non-dividing cells such as skeletal muscle fibers and central neurons [31]. Replication is generally thought to take place via a strand-asynchronous mechanism involving two unidirectional, independent origins $[32,33]$. Synthesis starts at the origin of $\mathrm{H}$-strand replication $\left(\mathrm{O}_{\mathrm{H}}\right)$ in the D-loop and proceeds along the parental L-strand to produce a full daughter $\mathrm{H}$-strand. When the second origin $\left(\mathrm{O}_{\mathrm{L}}\right)$ at two thirds of the way around the genome is reached, DNA synthesis of the L-strand initiates in the opposite direction. Recently, however, a bidirectional mode of mtDNA replication has been proposed [34, 35]. This second mechanism involves a coupled leading- and laggingstrand synthesis and is reported to exist along with the strand-asynchronous mechanism.

MtDNA replication is achieved by a number of nuclearencoded proteins. First of all, the only DNA polymerase present in mammalian mitochondria: polymerase $\gamma$. Polymerase $\gamma$ is a heterotrimer consisting of a catalytic subunit with proof-reading ability (POLG) and two identical accessory subunits (POLG2) that bind DNA and increase the processivity of POLG. Second, Twinkle is a $5^{\prime}$ to $3^{\prime}$ DNA helicase that unwinds double-stranded mtDNA and thereby plays a role in mtDNA maintenance and regulation of mtDNA copy number. Third, the mitochondrial singlestranded binding protein (mtSSB) is thought to maintain the integrity of single-stranded regions of DNA at replication forks and to stimulate the activity of Twinkle and polymerase $\gamma$. Additionally, several topoisomerases regulate supercoiling of mtDNA. Furthermore, mtDNA ligase III is involved in replication as well as repair of the mitochondrial genome. For replication initiation, RNA primers are needed. An as yet unidentified mtDNA primase likely provides the 


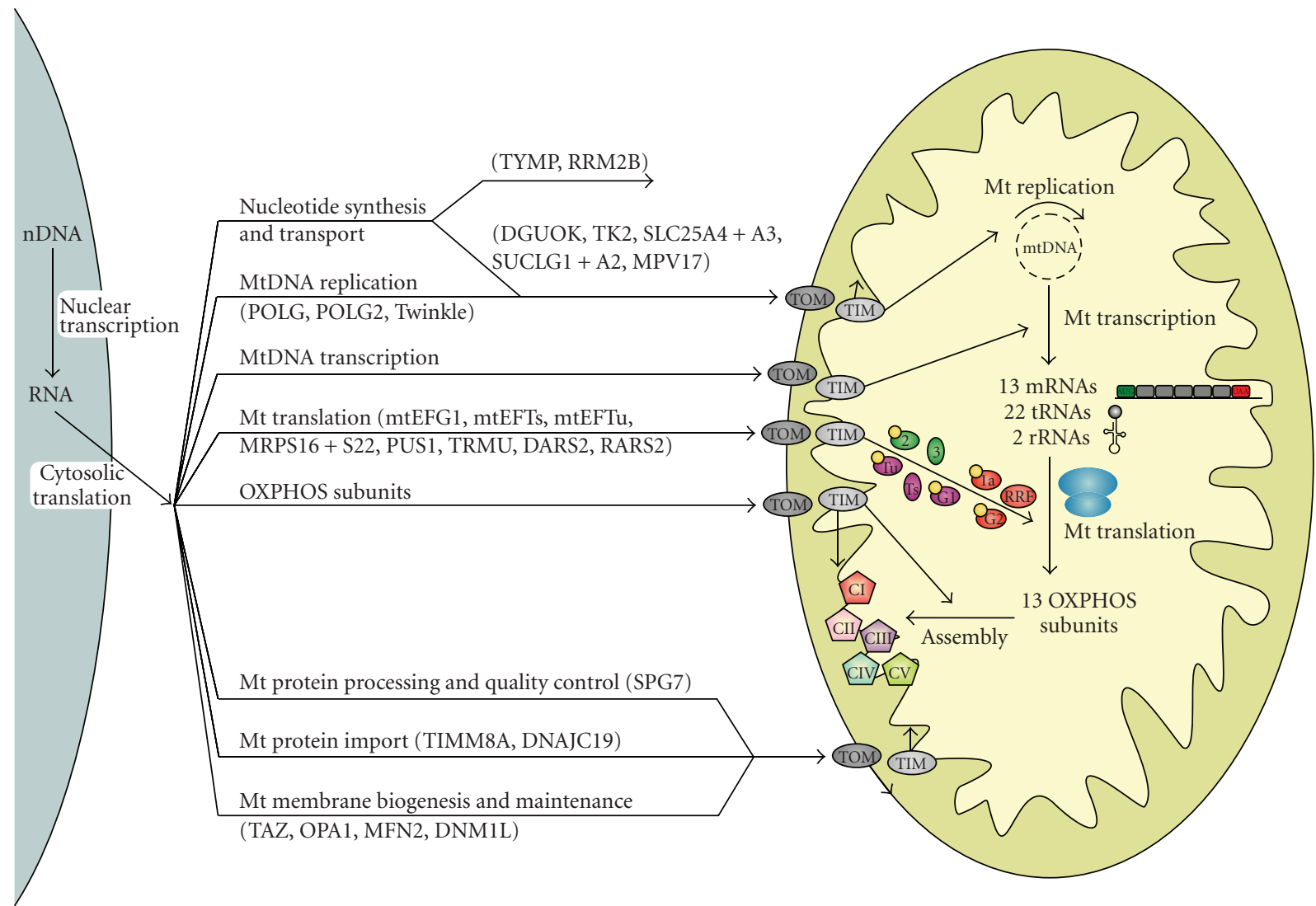

FIGURE 1: Schematic overview of the processes involved in mitochondrial translation and the biogenesis of the OXPHOS system. Before translation can take place in the mitochondrion, the mtDNA needs to be maintained, replicated and transcribed and numerous nDNAencoded proteins have to be imported into the mitochondrion for these processes and for mitochondrial translation itself (see Figure 2 for more details on mitochondrial translation and its components depicted here). For the formation of the OXPHOS system, the nDNA- and mtDNA-encoded subunits need to be synthesized, imported, inserted into the inner membrane and assembled into enzyme complexes. The 13 mRNAs depicted refer to 9 monocistronic and 2 dicistronic transcripts. Proteins implicated in mitochondrial disorders are mentioned in brackets (also see Table 1). CI-CV = complex I-V of the OXPHOS system; TIM and TOM = translocase of the inner and outer mitochondrial membranes.

RNA primer for L-strand synthesis, whereas the mitochondrial transcription machinery is involved in RNA primer formation for H-strand synthesis (see Section 2.3). RNase mitochondrial RNA processing endonuclease (RNase MRP) and endonuclease $G$ are implicated in processing of the precursor RNA primers for $\mathrm{H}$-strand replication. Last, RNase $\mathrm{H} 1$ has been proposed to be involved in replication of the mitochondrial genome by removal of the RNA primers. Ligase III, RNase MRP and RNase $\mathrm{H} 1$ are not specific mitochondrial proteins; they are also located in the cell nucleus. For a more detailed description of mitochondrial replication see a review by Graziewicz et al. [36].

Furthermore, various other proteins are indirectly involved in the maintenance of mtDNA either through protecting the mitochondrial genome, repairing mtDNA damage, or supplying nucleotide pools. Firstly, the protection of the mitochondrial genome. MtDNA is packaged into protein-DNA complexes called nucleoids, which are believed to be the units of mtDNA transmission and inheritance $[37,38]$. Among the nucleoid components are proteins involved in the maintenance, replication and/or transcription of mtDNA, such as $\mathrm{mtSSB}$, Twinkle, POLG and TFAM (mitochondrial transcription factor A). Secondly, mtDNA repair is crucial to avoid accumulation of damage to the rapidly replicating mitochondrial genome. Mitochondria possess multiple repair mechanisms, but these are beyond the scope of this review (detailed descriptions of mtDNA repair have been published previously $[39,40])$. Thirdly, a proper balance of the mitochondrial (deoxy)nucleoside triphosphate $((\mathrm{d}) \mathrm{NTP})$ pools, accomplished by mitochondrial transport proteins and salvage pathway enzymes, is also essential for mtDNA maintenance and replication (for an overview of mitochondrial dNTP metabolism and all proteins involved, see [41]). Shortage and/or imbalance of the dNTP pool could affect the efficiency and accuracy of mitochondrial replication. Additionally, disturbances of the NTP pool may interfere with replication by affecting the synthesis of the RNA primers necessary for replication initiation. This could subsequently lead to deletions in the mtDNA or depletion (i.e., reduced copy number) of 
the mitochondrial genome. A number of mitochondrial disorders are caused by defects in the mitochondrial dNTP metabolism due to mutations in the following nine nuclear genes: DGUOK, TK2, TYMP, SLC25A4, SLC25A3, SUCLG1, SUCLA2, RRM2B, and MPV17 (for reviews see $[13,42,43])$. Mitochondrial deoxyguanosine kinase (DGUOK) and thymidine kinase (TK2) catalyze the first step in the salvage pathways of pyrimidine and purine deoxynucleosides, respectively. In the salvage pathway, deoxynucleosides are activated by stepwise phosphorylation leading to formation of the dNTPs. The cytoplasmic enzyme thymidine phosphorylase (TYMP) catalyzes the reversible phosphorylation of thymidine and thereby regulates the availability of thymidine for DNA synthesis. Additionally, adenine nucleotide translocators (ANT) are needed to regulate the concentration of adenine nucleotides by exchanging ATP for ADP in and out of the mitochondrial matrix; SLC25A4 (ANT1) is the heart and skeletal muscle specific isoform. The mitochondrial phosphate carrier SLC25A3 transports inorganic phosphate into the mitochondrial matrix. SUCLG1 and SUCLA2 encode the $\alpha$ - and $\beta$-subunits of the Krebs cycle enzyme succinate-CoA ligase (SUCL). Defects in these genes could lead to mtDNA depletion through decreased activity of the mitochondrial nucleotide diphosphate kinase (NDPK), which functions in the last step of the mitochondrial dNTP salvage pathway and associates with SUCL. The p53R2 subunit (encoded by RRM2B) of the cytosolic enzyme ribonucleotide reductase is required for de novo deoxyribonucleotide synthesis in nonproliferating cells, thereby supplying dNTPs for nDNA repair and mtDNA synthesis. Finally, the mitochondrial inner membrane protein MPV17 is also involved in dNTP metabolism, with defects causing mtDNA depletion; the exact function of MPV17 remains to be elucidated, however. In addition to disturbed homeostasis of mitochondrial dNTP pools, mtDNA instability can naturally be caused by mutations in genes affecting mtDNA replication directly. Mutations have been reported in POLG, POLG2, and C10orf2 (Twinkle), with $P O L G$ being the most important contributor [13].

\subsection{Transcription of $m t D N A$. Transcription originates from} three promoters: two $\mathrm{H}$ strand promoters (HSP1 and HSP2) and one L strand promoter (LSP). The HSP1 and LSP are located in the D-loop, whereas HSP2 is located downstream of HSP1 close to the $5^{\prime}$ end of the $12 \mathrm{~S}$ rRNA gene. Transcription from both the HSP2 and LSP generates polycistronic molecules covering nearly the entire $\mathrm{H}$ or L strand, corresponding to 12 protein-coding genes, 14 tRNA genes and 2 rRNA genes (HSP2) or 1 protein-coding gene and 8 tRNA genes (LSP). Additionally, transcription from the LSP produces the RNA primers necessary for initiating mtDNA replication of the $\mathrm{H}$-strand. Transcripts derived from HSP1, on the other hand, contain mainly the $12 \mathrm{~S}$ and $16 \mathrm{~S}$ rRNAs. The basic human mitochondrial transcription machinery consists of three components: mtRNA polymerase (POLRMT), TFAM and either mitochondrial transcription factor B1 (TFB1M) or B2 (TFB2M). Promoter recognition and transcription initiation require the simultaneous presence of these three factors, however, the precise contribution of each has not yet been fully determined $[44,45]$. Termination of transcription appears to be regulated by multiple termination factors, but the exact mechanism and all factors involved still need to be elucidated $[45,46]$. Termination sites have been identified for transcription from HSP1 and HSP2; the two proteins binding to the HSP2 termination site await identification. Even though the mitochondrial transcription termination factor MTERF1 (or MTERF) has been shown to bind the HSP1 termination site (at the $3^{\prime}$ end of the $16 \mathrm{~S}$ rRNA gene) and be required for HSP1 transcription termination in vitro, it seems to block L strand transcription more effectively than transcription from the $\mathrm{H}$ strand; the precise function of the protein in vivo is unclear. Recently, MTERF1 was found to be essential for transcription initiation in vitro, which led to the hypothesis that MTERF1 regulates and promotes transcription at HSP1 by forming a loop between the MTERF1 initiation and termination binding sites. This way it helps favor a higher synthesis rate of rRNAs compared to mRNAs from the $\mathrm{H}$ strand. Furthermore, MTERF1 appears to modulate mtDNA replication pausing; its dual role could be important for coordination of replication and transcription [47]. Three homologs of MTERF1 and thus potential mitochondrial transcription termination factors have been identified: MTERF2 (or MTERFD3 or MTERFL), MTERF3 (or MTERFD1) and MTERF4 (or MTERFD2) [48]. MTERF2 is proposed to regulate cell growth through modulation of mitochondrial transcription [49]. MTERF2 shows the opposite expression pattern in response to serum compared to MTERF1, suggesting that they have divergent roles. Additionally, MTERF2 was found to be present in nucleoids, displaying non sequence-specific DNA-binding activity [50]. Contrastingly, Wenz et al. demonstrated specific binding of MTERF2 to the HSP promoter region [51]. Furthermore, MTERF2 knock-out resulted in decreased mitochondrial transcription and mRNA levels. MTERF3, on the other hand, has been shown in mouse in vivo and in human in vitro to function as a negative regulator of transcription initiation through interaction with the mtDNA promoter region [52]. Moreover, MTERF3 knock-down in Drosophila led to a decreased rate of mitochondrial protein synthesis, possibly through downregulation of TFB1M (see Section 3.3 for more information on TFB1M's function in translation) $[46,53]$. In summary, the current view is as follows: MTERF1 through 3 share a common binding site in the D-loop; both MTERF1 and 2 promote transcription initiation, whereas MTERF3 inhibits it; all three factors are needed to maintain optimal transcript levels and thereby ensure proper functioning of the OXPHOS system. The role of MTERF4 has not been investigated in detail, however, it appears to bind mtDNA in the D-loop region and form a stable homodimer with a putative RNA methyltransferase [54].

Processing of the polycistronic primary transcripts is thought to require four enzymes. The tRNA genes mark most of the junctions between mitochondrial protein-coding and rRNA genes. According to the tRNA punctuation model, the secondary structures of the tRNA sequences provide the signals for endonucleolytic excision of the tRNAs, yielding 
most of the tRNAs, mRNAs and rRNAs [55]. This initial processing step is performed by the mitochondrial RNase $\mathrm{P}$ ( $5^{\prime}$-end endonucleolytic cleavage) and tRNase Z ( $3^{\prime}$-end cleavage) enzymes. Maturation of the excised tRNAs is completed by addition of a CCA triplet to their $3^{\prime}$-end, which is catalyzed by an ATP(CTP):tRNA nucleotidyltransferase. After post-transcriptional modification and correct folding of the tRNAs, the amino acid can be attached to the CCA triplet by the corresponding aminoacyl-tRNA synthetase. The tRNA acceptor stem and the anticodon play important roles for the recognition of the tRNA by the appropriate synthetase. During or immediately after cleavage of the tRNAs, the rRNAs and mRNAs are polyadenylated by a mitochondrial poly(A) polymerase. This post-transcriptional modification creates the stop codons for some mRNAs and may also be necessary for stabilization of some RNAs (for a review see Montoya et al. [56]). In this way, 9 monocistronic and 2 dicistronic mRNA transcripts are formed. Another important post-transcriptional process is RNA degradation, which is required to control RNA levels and eliminate processing by-products and aberrant transcripts [57]. Nevertheless, the players involved and the exact mechanism have yet to be revealed. SUV3 and polynucleotide phosphorylase are possible candidates $[58,59]$.

Until now, no mutations causing mitochondrial disease have been reported in genes coding for proteins involved in mitochondrial transcription. Nonetheless, a mutation in the MTERF1 binding site (in the tRNA ${ }^{\mathrm{Leu}(\mathrm{UUR})}$ gene) is associated with the mitochondrial disorder MELAS (mitochondrial myopathy, encephalopathy, lactic acidosis and stroke-like episodes). This mutation reduces the binding affinity for MTERF1 and results in a drastic impairment of transcription termination in vitro, however, in vivo the transcription termination defect could not be confirmed [60,61]. Furthermore, TFB1M modifies the phenotypic expression of the deafness-associated 1555A $>\mathrm{G}$ mtDNA mutation (see Section 3.3). Additionally, post-transcriptional modification of tRNAs is disturbed in patients with mitochondrial myopathy and sideroblastic anemia (MLASA) due to a mutation in pseudouridylate synthase PUS1 [14, 17]. PUS1 converts uridine into pseudouridine in cytosolic as well as mitochondrial tRNAs. Recently, mutations in TRMU, a mitochondria-specific enzyme that is required for the 2thiolation on the wobble position of the tRNA anticodon, were detected in patients with acute liver failure in infancy [24]. Previously, TRMU was identified as another nuclear modifier gene for the mitochondrial $12 \mathrm{~S}$ rRNA mutation $1555 \mathrm{~A}>\mathrm{G}$ [62]; see Section 5.2 for more details on defects in the latter two genes.

2.4. Import of nDNA Encoded Proteins. Most mitochondrial proteins, including all proteins involved in mitochondrial translation, are encoded in the nucleus and therefore have to be transported to and imported into the mitochondrion. Cytosolic chaperones, such as heat shock proteins Hsp70 and Hsp90, guide the precursor proteins to translocation channel receptors on the mitochondrial surface, keep the proteins unfolded to prevent aggregation and enable entrance into the translocation channels. Alternatively, preproteins seem also to be imported into mitochondria in a co-translational manner [63-67]. These proteins, produced on ribosomes bound to the outer mitochondrial membrane, are almost exclusively of prokaryotic origin $[68,69]$. The cytoplasmic and mitochondrial translation machineries are suggested to be localized in close proximity on either side of the mitochondrial membranes, thereby allowing efficient assembly of the OXPHOS system [70]. Import and sorting of nDNAencoded proteins into mitochondria is achieved by translocases in the outer and inner mitochondrial membrane [71, 72]. The translocase of the outer mitochondrial membrane (TOM complex) forms the entrance for basically all nuclearencoded mitochondrial proteins. After passing through the TOM complex, the preproteins can follow various routes depending on their targeting signals: (1) outer membrane proteins are integrated into the membrane by the sorting and assembly machinery (SAM complex); (2) translocation to the intermembrane space is mediated by the TIM23 complex (translocase of the inner mitochondrial membrane) or by components in the intermembrane space; (3) matrix proteins reach their destination through the TIM23 channel; (4) for inner membrane proteins there are three pathways, (a) insertion by the TIM22 complex, (b) lateral integration after arrest at the TIM23 complex, and (c) import into the matrix via TIM23 followed by export to the inner membrane (see Section 4.2 for more information on the export to the inner membrane). After translocation, mitochondrial targeting sequences are removed proteolytically and the proteins fold into their functional structures.

Two syndromes have been related to defects in mitochondrial import. Mutations in the gene for the translocase subunit TIMM8A (or DDP1) have been reported to result in the deafness dystonia syndrome or Mohr-Tranebjaerg syndrome (MTS) [73, 74]. TIMM8A is part of a small alternative TIM complex that is involved in the import of TIMM23, an essential constituent of the TIM23 complex, and a few other proteins [71]. Remarkably, no impairment of the OXPHOS system has been observed $[73,75]$. The exact mechanism by which TIMM8A mutations affect mitochondrial function remains to be clarified. Dilated cardiomyopathy with ataxia (DCMA) is caused by a mutation in DNAJC19, which is thought to be a homolog of yeast Tim14 [76]. Tim14 is an essential component of the TIM23 complex [77], suggesting that the underlying disease mechanism is defective import of nDNA-encoded proteins into the mitochondrion. However, this has not been verified yet.

\section{Mitochondrial Translation}

Although most of the proteins present in mitochondria are encoded by the nDNA, a few are encoded by the mtDNA and are synthesized by the separate mitochondrial translation system. The human mitochondrial genome codes for 22 tRNAs, 2 rRNAs and 13 polypeptide subunits of the enzyme complexes I, III, IV, and V [26]. Whereas the components and mechanisms of translation are well characterized for bacterial and eukaryotic cytoplasmic systems, far less is known about mitochondrial protein synthesis due to the lack of a proper in vitro mitochondrial translation system. For 
a review on mammalian mitochondrial protein synthesis, insertion and disorders associated with these processes see Pérez-Martínez et al. [78].

The mitochondrial translation more closely resembles its prokaryotic than its eukaryotic cytoplasmic counterpart. However, the protein-synthesizing system of mitochondria has a number of interesting characteristics not observed in prokaryotes or the eukaryotic cell cytoplasm. First of all, mitochondria use a genetic code that has several distinct differences from the universal code [79]. For example, human mitochondria use the universal arginine codons AGG and AGA, in addition to UAA and UAG, for termination. Furthermore, UGA serves as a codon for tryptophan rather than as a stop codon. Additionally, AUA has been reassigned to Met rather than serving as an Ile codon. Secondly, also the mitochondrial mRNAs have unusual features: they contain no or very few $5^{\prime}$ untranslated nucleotides [80], are uncapped [81], and contain a poly(A) tail that immediately follows or even forms part of the stop codon [55]. The small subunit of mitochondrial ribosomes (mitoribosomes) appears to bind these mRNAs tightly in a sequence-independent manner and in the absence of initiation factors or initiation tRNA [82], unlike the prokaryotic [83] and eukaryotic cytoplasmic [84] systems. Thirdly, mitochondria use a simplified decoding mechanism that allows translation of all codons with only 22 tRNAs instead of the 31 predicted by Crick's wobble hypothesis $[26,85]$. Fourthly, mammalian mitochondria use a single tRNA $^{\text {Met }}$ for both the initiation and elongation phases (depending on the presence or absence of a formyl group, resp.), whereas not only in the prokaryotic and eukaryotic cytoplasmic translation systems but also in the mitochondria of most lower eukaryotes two specialized tRNA $^{\text {Met }}$ species exist [86].

In this section, we will cover in subsequent paragraphs the components of the protein synthesis machinery, the translation process steps, its regulation, and additional roles of mitochondrial translation proteins outside the translation process.

3.1. The Mitochondrial Translation Machinery. The basic mitochondrial translation machinery comprises mtDNAencoded rRNAs and tRNAs as well as many proteins coded for by the nuclear genome: (1) initiation, elongation and termination translation factors; (2) mitochondrial ribosomal proteins (MRPs); (3) mitochondrial aminoacyl-tRNA synthetases and methionyl-tRNA transformylase. These components will be described in more detail successively.

First of all, the translation factors. The exact functions of the mitochondrial translation factors will be discussed in Section 3.2. Bacterial translation initiation involves three factors: IF1, IF2, and IF3. Whereas IF1 and IF2 are considered to be universal and essential initiation factors, IF3 orthologs have not been found in archaea or the cytoplasm of eukaryotes [87, 88]. Surprisingly, the mitochondrial translation machinery consists of two initiation factors orthologous to prokaryotic IF2 [89] and IF3 [90] and despite extensive searches, no IF1 ortholog has been detected [91]. Recently, mitochondrial IF2 (mtIF2) was demonstrated to perform functions of both bacterial IF1 and IF2; a conserved 37 amino acid insertion in mtIF2 seems to have assumed the role of IF1, facilitating the bond between mtIF2 and the mitoribosome and the formation of the initiation complex [92]. All three prokaryotic elongation factors have also been found in human mitochondria: mtEFTu, mtEFTs, and mtEFG [9395]. In contrast to most bacteria, which have merely one EFG protein that acts during both the elongation and termination phases of the translation process, mitochondria contain two EFG homologs, mtEFG1 and mtEFG2 [93], that are $35 \%$ identical [91]. The importance of mtEFG1 for mitochondrial protein synthesis has been demonstrated by mtEFG1 defects in patients with a mitochondrial disorder $[15,22,25]$ and its translocation activity was shown in vitro [96]. Even though expression levels of mtEFG2 are greatest in skeletal muscle, heart and liver [93], three tissues with high metabolic energy rates, the functional significance of mtEFG2 for mitochondrial translation is not entirely clear. Notably, deletion of the mtEFG2 ortholog in yeast $(M E F 2)$ does not lead to impaired mitochondrial protein synthesis and respiratory defects, as is the case for $M E F 1$, the mtEFG1 yeast ortholog [97]. Moreover, complementation of $\mathrm{mtEFG} 1$ defects through overexpression of mtEFG2 could not be attained [15, 25], indicating that mtEFG2 might not play a role in the translocation step of mitochondrial translation. This was recently confirmed by Tsuboi et al., who demonstrated that mtEFG1 specifically catalyzes translocation, whereas mtEFG2 has an essential function in ribosome recycling and lacks translocation activity [98]. Thus the dual role of prokaryotic EFG is distributed between mtEFG1 and mtEFG2. Bacteria contain four factors responsible for translation termination: the three release factors RF1-3 and the ribosome recycling factor RRF [99]. The release factors are divided into two classes, with class I factors (RF1 and RF2) promoting codon-specific hydrolysis of peptidyl-tRNA and class II factors (RF3) lacking specificity but stimulating the activity of class I factors and their dissociation from the ribosome. Bacteria utilize three stop codons; both class I release factors recognize UAA, whereas UAG and UGA are decoded only by RF1 or RF2, respectively. In the eukaryotic cytosol, two release factors, RF1 and RF3 orthologs, are required for the termination step with just one class I factor recognizing all three stop codons [100]. A factor equivalent to bacterial RRF appears to be absent. The termination process in mitochondria, on the other hand, has not yet been fully elucidated. Two release factors, mtRF1 and mtRF1a (or HMRF1L), and a recycling factor ( $\mathrm{mtRRF}$ ) have been identified and partly characterized [101-104]. Being involved in ribosome recycling instead of the elongation phase, mtEFG2 should be added to this list and be renamed mtRRF2 [96]. MtRF1 was proposed to be a member of the class I release factors based on bioinformatic analyses [103], but recently this factor failed to exhibit release factor activity in vitro and in vivo [101, 102]. Nonetheless, the newly identified release factor mtRF1a was shown to terminate translation at UAA and UAG codons, analogous to bacterial RF1. Thus the question whether a mitochondrial release factor exists that recognizes the other two mitochondrial stop codons, AGG and AGA, which are found in just two of the mitochondrial transcripts, remains 
unresolved. The fact that release activity was not observed for mtRF1 could be attributed to the use of bacterial and yeast systems that naturally do not terminate with these codons [102]. Therefore, the possibility remains that mtRF1 is indeed a mitochondrial release factor. Alternatively, AGA and AGG might not be used as stop codons since there is no experimental data supporting this and remarkably, in rat and mouse mitochondria the codons AGA and AGG are unassigned and UAA appears to be the single stop codon utilized $[105,106]$. The terminal AGA and AGG codons could be edited posttranscriptionally, creating UAG stop codons, which could then be decoded by mtRF1a [101]. Whether mitochondria contain a class II factor equivalent to bacterial RF3 is unclear.

Secondly, the mitoribosomes that are made up of rRNAs and MRPs and comprise two subunits, the small (SSU or $28 \mathrm{~S}$ ) and the large (LSU or $39 \mathrm{~S}$ ) subunit. The human mitoribosome consists of 2 rRNAs (12S and 16S) and around 81 MRPs [107]. Mammalian mitoribosomes differ markedly from bacterial, cytosolic and even from other mitochondrial ribosomes [108]. They lack nearly half the rRNA present in bacterial ribosomes, resulting in a sedimentation coefficient of 55S compared with $70 \mathrm{~S}$ in bacteria. Nevertheless, mitoribosomes contain a correspondingly higher protein content due to enlargement of proteins and recruitment of numerous extra proteins, causing a greater molecular mass and size than bacterial ribosomes. Most of these enlarged and supernumerary proteins do not seem to compensate for the missing rRNA segments since they occupy new positions in the mitoribosome [109], suggesting that they perform mitochondria-specific functions.

Third, the mitochondrial tRNAs. In general, human mitochondrial tRNAs deviate from the canonical tRNAs, but still fold into mostly classical cloverleaf secondary structures and presumably also into L-shaped tertiary structures [110]. Mitochondrial tRNAs are shorter than bacterial or eukaryotic cytoplasmic tRNAs, have large variations in the size of the D- and T-loops, and lack multiple conserved nucleotides that are involved in classical tertiary interactions creating the L-shape, which possibly results in a weaker tertiary structure. Post-transcriptional base modification appears to be more important for the proper tertiary structure and functioning of mitochondrial tRNAs compared with cytosolic tRNAs [111]. Certain mitochondrial tRNAs will consequently be completely non-functional when they lack the post-transcriptional modification resulting in an aberrant structure [112]. Furthermore, modifications can improve tRNA specificity and its recognition by mRNA codons and to a lesser extent by aminoacyl-tRNA synthetases $[113,114]$. In total, 19 mitochondrial aminoacyl-tRNA synthetases have been identified, of which two are encoded by the same gene as the cytosolic enzyme [115]. Only the gene for mitochondrial glutaminyl-tRNA synthetase has not been found yet. After aminoacylation, the tRNA ${ }^{\text {Met }}$ needs to be formylated by methionyl-tRNA transformylase to initiate mitochondrial translation.

Although the core components of the mitochondrial translation machinery have been identified, many more factors are likely to be involved, directly or indirectly, and have yet to be discovered. Recently, Davies et al. showed that pentatricopeptide repeat domain protein 3 (PTCD3) associates with the mitoribosomal SSU and is necessary for mitochondrial protein synthesis [116]. The precise function of PTCD3 remains to be clarified, however.

3.2. The Mitochondrial Translation Process. The basic model of protein synthesis is derived from studies in bacteria (see $[87,99,117]$ for reviews on the processes involved in protein synthesis). Our understanding of the mechanisms of mitochondrial translation is based on this model and additional studies in mitochondria.

Protein synthesis is divided into three phases: initiation, elongation and termination. The exact starting mechanism of the translation process in mitochondria is poorly understood. Due to the unusual characteristics of mitochondrial mRNAs, neither the Shine-Dalgarno sequence observed in prokaryotes nor the 7-methylguanlyate cap structure found in the eukaryotic cell cytoplasm can facilitate ribosome binding and direct the ribosome to the start codon. It is thought that the mRNA entry gate on the SSU of the mitoribosome has evolved in such way that it recognizes the unique mitochondrial mRNAs with their unstructured $5^{\prime}$ sequences $[109,118]$. Many questions remain concerning the precise sequence of events during the initiation phase in mammalian mitochondria. In the current model, mitochondrial translation factor mtIF3 catalyzes the dissociation of the mitoribosome into its two component subunits (Figure 2, step 1), which may be an active rather than a passive process, thereby permitting the assembly of the initiation complex while preventing premature binding of the LSU $[90,119]$. Possibly, complete subunit dissociation is not essential for initiation of translation, however, the subunit interface must become accessible for fMet-tRNA ${ }^{\mathrm{Met}}$ and mRNA binding. It has been postulated that the first step in initiation complex formation is sequence-independent binding of mRNA to the SSU (Figure 2, step 2) [82, 120]. MtIF3 is thought to assist the mRNA to bind the SSU so that the start codon (AUG) is correctly positioned at the peptidyl (P) site of the mitoribosome. Both fMet-tRNA and mtIF2 can bind weakly to the SSU in the absence of mRNA and mtIF3 is hypothesized to prevent or correct the premature binding of these components [119]. The binding of fMet-tRNA ${ }^{\mathrm{Met}}$ to the SSU requires mtIF2, which is markedly enhanced by GTP (Figure 2, step 3) [121, 122]. Recombining of the LSU with the SSU (Figure 2, step 4) probably stimulates the dissociation of mtIF3 (Figure 2, step 5) [123]. Additionally, GTP hydrolysis on mtIF2 is triggered by the LSU, leading to its release from the complex (Figure 2, step 6). The initiation phase is now complete and translation can proceed with the elongation phase.

The basic steps in the elongation phase are the same in bacteria and mitochondria, however, the equilibrium dissociation constants for interactions between mtEFTu and its ligands differ considerably between the prokaryotic and mitochondrial systems $[124,125]$. The relative ratios of the elongation factors are important for efficient translation $[21,25,126]$. These ratios differ between tissues and can be adapted in response to dysfunction of one of the elongation 


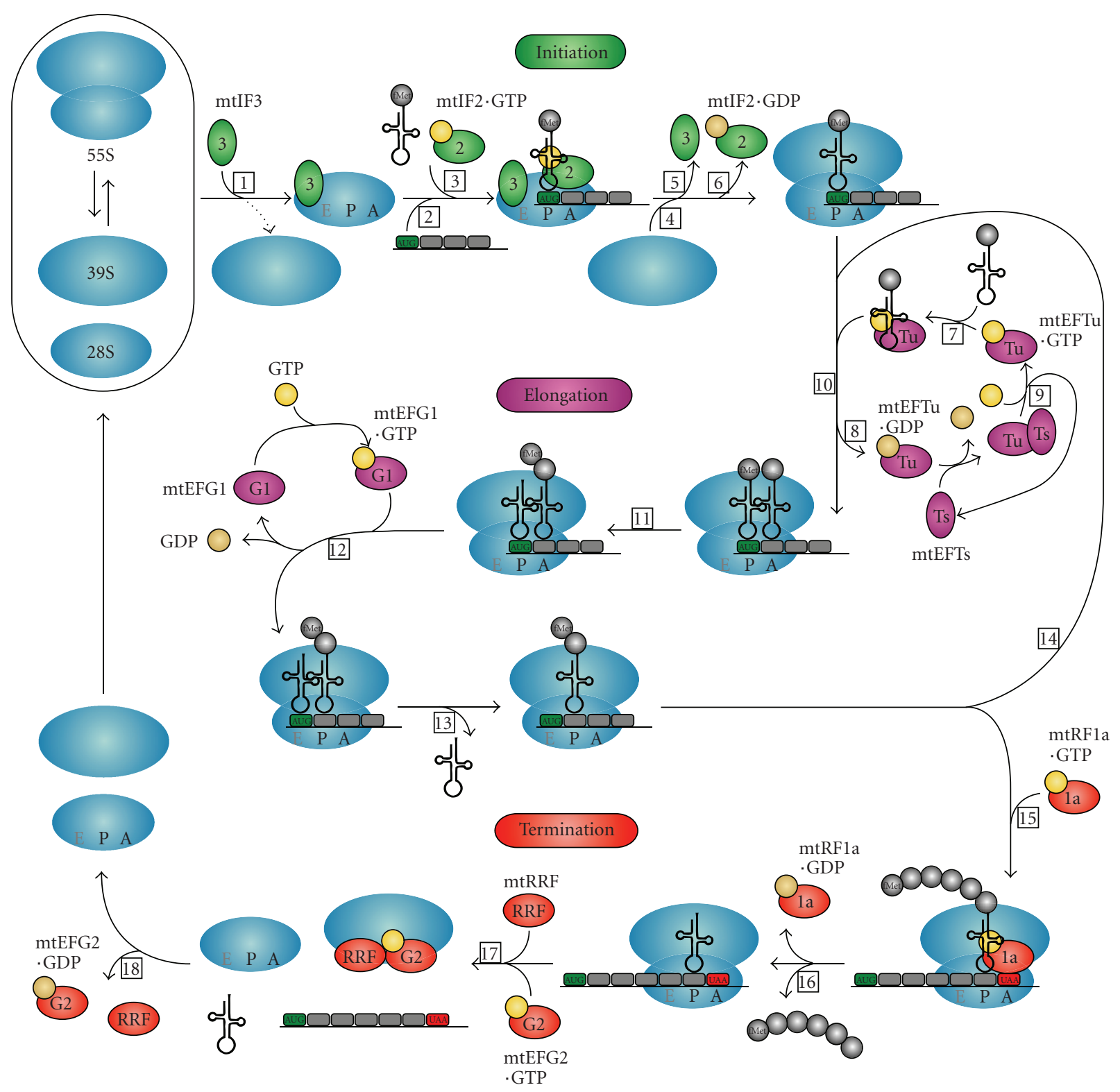

FIGURE 2: Diagram of human mitochondrial protein synthesis. The three phases of mitochondrial translation-initiation, elongation and termination - and all translation factors involved are represented in this figure. See Section 3.2 in the text for a detailed description of all steps (numbered in boxes) of the mitochondrial translation process. Initiation, elongation and termination factors are represented by green, purple and red ovals, respectively. GTP and GDP are shown in yellow and beige circles, respectively.

factors [25]. Elongation factor mtEFTu forms a ternary complex with GTP and an aminoacylated tRNA (Figure 2, step 7). It is proposed to be critical for translational accuracy through surveillance of aminoacyl-tRNAs for misacylation [127]. MtEFTu protects the tRNA from hydrolysis and, after a proofreading step, carries it to the mitoribosomal aminoacyl or acceptor (A) site for the decoding of mRNA by codonanticodon interactions on the SSU (Figure 2, step 10). When the codon-anticodon recognition occurs, GTP hydrolysis on mtEFTu is stimulated by the mitoribosome, resulting in the release of $\mathrm{mtEFTu}$-GDP (Figure 2, step 8). The nucleotide exchange protein mtEFTs converts mtEFTu-GDP in active mtEFTu-GTP (Figure 2, step 9). Following the release from
mtEFTu, the $3^{\prime}$ end of the aminoacyl-tRNA moves into the peptidyl transferase center of the LSU where peptide bond formation is catalyzed, adding one amino acid to the growing peptide (Figure 2, step 11). The elongation factor mtEFG1 with bound GTP catalyzes the translocation step by conformational changes in both mtEFG1 and the mitoribosome, during which the $\mathrm{A}$ and $\mathrm{P}$ site tRNAs move to the $\mathrm{P}$ and exit (E) sites of the mitoribosome and mRNA is advanced by one codon (Figure 2, step 12). Subsequently, the tRNA leaves the mitoribosome via the E site (Figure 2, step 13) and a new elongation cycle can start (Figure 2, step 14). Whether the mitoribosome contains an actual $\mathrm{E}$ site is uncertain. The bovine mitoribosomal structure and a 
comparative analysis of ribosome sequences revealed that the mitoribosomal $\mathrm{E}$ site deviates substantially from the prokaryotic and eukaryotic cytosolic situations $[109,128,129]$. Based on these findings, the $\mathrm{E}$ site has been suggested to be very weak or even absent in the mitoribosome. Moreover, the mitoribosomal polypeptide exit tunnel is markedly different, allowing premature exposure of the nascent polypeptide to the mitochondrial matrix or membrane before reaching the conventional exit site [109]. Whether all or some nascent polypeptide chains emerge prematurely from the peculiar mitoribosomal exit tunnel is currently unknown.

The third and last step in protein synthesis, termination, begins when a stop codon (UAA, UAG, AGA or AGG) is encountered in the A site. A mitochondrial release factor, mtRF1a or possibly also mtRF1 or an as yet unidentified protein, recognizes the stop codon (Figure 2, step 15) and causes the protein that is attached to the last tRNA molecule in the P site to be released (Figure 2, step 16). The ester bond between the tRNA and the nascent polypeptide is hydrolyzed, presumably by the peptidyl transferase center on the LSU triggered by the release factor, and this process is catalyzed by GTP. After release of the newly synthesized protein, mtRRF and mtEFG2.GTP together enable the mitoribosomal subunits, tRNA and mRNA to dissociate from each other (Figure 2, step 17), making the components available for a new round of protein synthesis. GTP hydrolysis is required for the release of mtRRF and mtEFG2.GDP from the LSU (Figure 2, step 18) [96].

3.3. Regulation of Mitochondrial Translation. In yeast, nuclear-encoded, gene-specific activation factors are required for mitochondrial translation initiation [130, 131]. Currently, translational activation factors have been found for (nearly) all eight yeast mtDNA-encoded proteins and synthesis of some proteins, for example, Cox3, depends on multiple activation factors [130-132]. These activators bind to the $5^{\prime}$ untranslated leader ( $5^{\prime}$-UTL) sequences of the mRNA, probably to assist in positioning the mitoribosomes over the initiation codon. All translational activator proteins studied so far are integral membrane proteins or bound to the mitochondrial inner membrane, suggesting that they are also involved in tethering mitochondrial translation to the inner membrane. This way they can promote cotranslational insertion of newly synthesized proteins and subsequent assembly into the OXPHOS complexes. Thus the yeast mitochondrial translational activators regulate not only the levels of mitochondrially synthesized gene products, but also the location of mitochondrial translation.

The mechanisms of human mitochondrial translation regulation are poorly understood. Human mitochondrial mRNAs lack $5^{\prime}$-UTL sequences and until recently no clear evidence was found for the existence of mRNA-specific translation activators, which suggests that modulation of mitochondrial protein synthesis in humans involves other strategies than in yeast [133]. Genome-wide linkage analysis and chromosome transfer in a patient presenting with Leigh syndrome due to an isolated complex IV deficiency resulted in the identification of a human translational activator of the complex IV subunit COXI: CCDC44 or TACO1
[134]. A homozygous base insertion, creating a premature stop codon, led to severely decreased levels of TACO1 in patient fibroblasts. Consequently, only a small amount of COXI was synthesized despite normal concentrations of the COXI transcript, compromising complex IV assembly and activity. Remarkably, deletion of the TACO1 ortholog in yeast produced no respiration or mitochondrial translation defect. In contrast to the human situation, TACO1 is apparently not essential for respiration in yeast.

Furthermore, another potential translational activator for COXI has been identified in humans: a member of the pentatricopeptide (PPR) family, leucine-rich PPR-motif containing protein (LRPPRC, also known as LRP130). The PPR motif has been found in proteins that interact with RNA, such as POLRMT, which contains two PPR motifs in the amino-terminal domain (ATD) [135]. LRPPRC has been postulated to be a homolog of Pet309 [136], the yeast mitochondrial translational activator for COX1 [137]. Mutations in LRPPRC lead to the neurodegenerative disorder Leigh Syndrome French-Canadian type (LSFC), with a deficiency of complex IV of the OXPHOS system [136]. LRPPRC appears to play a role in the translation and/or stability of COXI and COXIII mRNAs, similar to yeast Pet309 [138]. In addition to its role as translational activator, Pet309 might be involved in coupling mitochondrial transcription to translation through interaction with Nam1 [139], a protein that is postulated to stabilize and direct mRNAs to the mitochondrial inner membrane for translation [140] and that binds to the ATD of yeast mtRNA polymerase [135]. LRPPRC has been suggested to function together with heterogeneous nuclear ribonucleoprotein K (hnRNP K) and POLRMT in coupling the mitochondrial transcription and translation machineries in a manner analogous to the yeast system [141]. However, the situation is more complex than depicted here, encompassing additional proteins for which homology between yeast and human has not been identified yet. Moreover, LRPPRC binds not only mitochondrial but also nuclear mRNAs, indicating that it could be involved in coordinating nuclear and mitochondrial gene expression [142].

Nolden et al. proposed a negative-feedback loop mechanism for regulation of mitochondrial translation [143]. The ATP-dependent m-AAA protease plays an important role in quality control of mitochondrial inner membrane proteins. One of the substrates of this enzyme is the ribosomal protein MRPL32. Processing of MRPL32 by the m-AAA protease results in a tight association of MRPL32 with the inner membrane and allows completion of mitoribosome assembly in close proximity to the inner membrane. Maturation of MRPL32 seems to be required for mitochondrial translation since synthesis of mtDNA-encoded proteins was substantially impaired in cells lacking the m-AAA protease. Regulation of translation via the m-AAA protease could for instance take place when nuclear and mitochondrial gene expression are unbalanced. Excess respiratory subunits and other nonnative substrates of the m-AAA protease may then accumulate and compete with MRPL32 for binding to the protease. This will hamper MRPL32 processing, ribosome assembly, and finally mitochondrial translation. Accordingly, 
the amount of respiratory subunits available to the $\mathrm{m}$ AAA protease decreases and MRPL32 processing increases again. The importance of this regulation process has been demonstrated by loss-of-function mutations in paraplegin, a subunit of the human m-AAA protease, which result in the neurodegenerative disorder hereditary spastic paraplegia [144].

Possibly, TFB1M and TFB2M are involved in a retrograde pathway regulating mitochondrial biogenesis and function $[145,146]$. Overexpression of TFB2M resulted in increased TFB1M levels and consequently an increase in mitochondrial biogenesis. In addition to their transcriptional stimulatory activity, TFB1M and TFB2M have rRNA methyltransferase activity. Thus these factors are indirectly involved in mitochondrial protein synthesis via their ability to methylate the mitochondrial $12 \mathrm{~S}$ rRNA, which is important for mitoribosome activity. TFB1M has been identified as a nuclear modifier of the $1555 \mathrm{~A}>\mathrm{G}$ mutation in the $12 \mathrm{~S}$ rRNA gene that causes nonsyndromic or aminoglycoside antibiotic-induced deafness [147]. Presumably, altered or lack of methylation due to malfunctioning TFB1M can diminish the effect of the $1555 \mathrm{~A}>\mathrm{G}$ mutation on mitoribosome conformation. In vivo studies in mice revealed that TFB1M is an essential rRNA methyltransferase, needed for stability of the mitoribosomal SSU, that does not directly modulate transcription, whereas TFB2M is suggested to have transcriptional activation as its primary function [148]. Therefore, differential expression of these two factors could modulate not only transcription, but also replication (via the transcription factor activity) and translation (via the rRNA methyltransferase activity), and in this manner ensure a balance between the amounts of mitochondrial transcripts and fully assembled mitoribosomes [145, 148].

Mitochondria are under general nuclear control through transcription factors, such as nuclear respiratory factors 1 and 2 (NRF-1 and -2) [149]. These factors coordinate the expression of the nuclear and mitochondrial gene products required for oxidative phosphorylation and other essential mitochondrial functions. They act directly on nuclear genes coding for OXPHOS subunits as well as various nuclear genes encoding proteins involved in mtDNA replication, mitochondrial transcription or translation, by which they exert indirect control over expression of mitochondrial genes. Transcription factor CREB (cAMP response elementbinding protein) promotes transcription of mitochondrial (in addition to nuclear) genes after its import into the mitochondrion directly [150].

3.4. Functions of the Mitochondrial Translation Machinery beyond Translation. Initiation factor mtIF2 might be involved in mitochondrial mRNA degradation and apoptosis. The endoribonuclease RNase $\mathrm{L}$ is an important player in apoptosis induced by interferons (IFNs) [151]. After binding its IFN-induced activator, RNase L degrades single-stranded RNAs, leading to inhibition of protein synthesis. RNase L was shown to interact with mtIF2 and thereby modulate the stability of mitochondrial mRNAs, which appears to be essential for IFN $\alpha$-induced apoptosis [152]. RNase L is brought into association with the mitochondrial mRNA during their translation through interaction with mtIF2. In the presence of IFN $\alpha$, RNase L becomes activated and degrades mRNA, which can eventually result in apoptosis. An excess level of mtIF2 could hold RNase L away from the mRNAs, preventing their degradation and thus also inhibiting IFN $\alpha$-induced apoptosis.

In addition to its function in the elongation phase of the mitochondrial translation, mtEFTu has been reported to act as a chaperone [153]. It plays a role in protein quality control in mitochondria, as has been found for its cytosolic and prokaryotic counterparts. MtEFTu interacts with unfolded proteins, especially with misfolded, newly synthesized polypeptides, and is hypothesized to recruit these proteins to a mitochondrial protease complex for their degradation. This protease complex presumably consists of the homologs of the bacterial GroEL/ES (Hsp60 class) chaperone and $\mathrm{ClpA} / \mathrm{ClpP}$ protease systems, with which EFTu can interact via the heat shock protein Hsp31 [154].

Recently, human mitochondrial ribosomal protein MRPL12 was demonstrated to bind to POLRMT, which enhances transcription [155]. Free MRPL12, that is, MRPL12 not incorporated in the mitoribosome, appears to interact with POLRMT and consequently might coordinate the rate of mitochondrial transcription with the rate of mitoribosomal biogenesis. When the import rate of MRPs is exceeding the rate of mtDNA-encoded rRNA expression, free MRPL12 will accumulate and associate with POLRMT. Subsequently, the rate of mtDNA transcription increases, which rebalances the system.

Furthermore mitochondrial ribosomal proteins MRPS29 and MRPS30 seem to be bifunctional proteins [156]. These two proteins are the proapoptotic proteins death-associated protein 3 (DAP3) and programmed cell death protein 9 (PDCD9 or p52), respectively. Whether MRPS29 and/or MRPS30 are released from the mitoribosome and exported to the cytosol during apoptosis or whether they carry out their proapoptotic role while still associated with the mitoribosome is unknown. Possibly, inner membrane-associated mitoribosomes affect the mitochondrial permeability transition pores via MRPS29 and MRPS30 and thereby induce apoptosis.

\section{Posttranslational Processes Required for Functional OXPHOS Complexes}

After translation has taken place, the mtDNA-encoded and imported nDNA-encoded proteins need to be incorporated into the inner membrane to form a functional OXPHOS system. Mitochondria contain chaperones, proteases and assembly factors for particular OXPHOS complexes to aid in this process.

4.1. Quality Control by Chaperones and Proteases. The entire chaperone system represents a mechanism for quality control that determines the fate of all mitochondrial proteins: proteolytic degradation or folding and assembly. Chaperones from the Hsp60 and Hsp70 class bind to and stabilize (partially) unfolded or newly synthesized or imported proteins, thereby preventing their aggregation and facilitating their proper 
folding [157]. Hsp100/Clp family chaperones are involved in the re-solubilization of protein aggregates and unfolding of misfolded proteins, resulting in either refolding by other chaperones or degradation by proteases. Excess or nonnative proteins are degraded into peptides by ATP-dependent proteases and subsequently into amino acids by oligopeptidases [158]. Mammalian mitochondria have three major ATP-dependent proteases: Lon, Clp-like, and other AAA proteases. Both Lon protease and proteins from the Clp family are located in the matrix and contain proteolytic as well as chaperone activities. Two membrane-bound ATP-dependent AAA-proteases, active on the intermembrane space side (iAAA) or on the matrix side (m-AAA), are responsible for quality control of inner membrane proteins. Additionally, as mentioned in Section 3.3, they regulate mitochondrial biogenesis through selective processing of mitochondrial proteins, for example, MRPL32. The significance of these AAA proteases is demonstrated by the severe defects due to dysfunction of one of the AAA proteases found in several species. The prohibitin complex, consisting of Phb1 and $\mathrm{Phb} 2$ and also located in the inner membrane, is thought to act as a chaperone that stabilizes mitochondrially synthesized OXPHOS subunits against degradation by AAA proteases $[159,160]$. While the exact functions of the prohibitin complex remain poorly understood, its role in mitochondrial biogenesis and metabolism has been corroborated by numerous findings, such as different prohibitin expression levels depending on metabolic demand and lack of prohibitin leading to reduced mitochondrial membrane potential and instability of mtDNA-encoded OXPHOS subunits [160].

4.2. Protein Insertion into the Inner Membrane. A subset of mitochondrial inner membrane proteins that are synthesized in the cytosol are imported into the mitochondrial matrix prior to their export to the inner membrane; all other nuclear-encoded proteins are integrated directly into the inner membrane during import into the mitochondrion (also see Section 2.4). All proteins synthesized by the human mitochondrial translation system are destined for the inner membrane and become inserted through the same export machinery as used by nDNA-encoded proteins. At least half of the mitoribosomes are associated with the inner membrane [161] and it has been proposed that only membrane-bound mitoribosomes are translationally active [143]. It appears that mitochondrial gene products become inserted into the inner membrane as they are undergoing synthesis on mitoribosomes, that is, in a co-translational fashion [162-166]. However, the relative contributions of coand post-translational insertion and the exact mechanisms are unknown. The inner membrane protein Oxal plays an important role in insertion of both mitochondrial- and nuclear-encoded proteins from the mitochondrial matrix into the inner membrane $[167,168]$. Recently, the interaction of Oxal with the mitoribosome was concluded to involve at least the two yeast LSU proteins Mrp20 and Mrpl40, orthologs of bacterial ribosomal proteins L23 and L24 respectively, which are located close to the polypeptide exit tunnel $[169,170]$. Furthermore, mitoribosomal protein MRPL45 was postulated to function in the co-translational insertion of mtDNA-encoded proteins into the inner membrane [107]. The yeast ortholog of MRPL45, Mbal, associates with the inner membrane and is involved in protein insertion into the membrane in a concerted action with Oxa1, possibly by positioning the mitoribosomal exit tunnel at the right location for insertion [164, 171]. Nonetheless, mitoribosomes remain partially anchored to the mitochondrial inner membrane in absence of MRPL45 and Oxal, indicating that additional factors are involved in the membrane association [164]. One of these factors could be LETM1, leucine zipper EF-hand-containing transmembrane protein 1, located in the chromosomal region that is deleted in patients suffering from WolfHirschhorn syndrome [172]. It is the homolog of yeast inner membrane protein Mdm38, which has been proposed to function in an Oxa1-independent transport pathway across the inner membrane [173]. LETM1 was found to associate with MRPL36 and could thereby anchor the mitoribosome to the inner membrane [174]. Overexpression of LETM1 resulted in inhibition of mitochondrial biogenesis and ATP production. Conversely, LETM1 knockdown caused mitochondrial swelling, loss of tubular networks and disassembly of OXPHOS complexes I, III, and IV [175]. Much of the exact functions of LETM1 remain to be clarified, however, such as its role in cell viability and tumorigenesis, in addition to its potential interaction with the mitoribosome [174-176].

Coupling mitochondrial protein synthesis to insertion of the protein into the inner membrane will be advantageous for the efficient formation of OXPHOS complexes. As mentioned previously, transcription seems to be coupled to the translation system as well. A similar process called transertion, the coupled transcription-translation-insertion of proteins into and through membranes, is found in bacteria [177, 178]. Linking of these processes generates hyperstructures, which are assemblies of different types of (macro)molecules that form an organizational level intermediate between genes/proteins and whole cells [179]. Thus the mtDNA, transcription and translation machineries may be dynamically connected to the inner membrane into hyperstructures at assembly sites for the OXPHOS system.

4.3. Assembly of OXPHOS Complexes. Each OXPHOS complex has a specific assembly pathway, which involves chaperones that are not part of the functional complex but are implicated in its formation: the assembly factors. Up till now, 22 assembly factors have been identified and the list is still growing (see [180] for an overview, including defects in assembly): eleven for complex I (NDUFA12L or B17.2L [181], NDUFAF1 or CIA30 [182], NDUFAF2 [181, 183], NDUFAF3 or C3ORF60 [184], NDUFAF4 or C6ORF66 [185], Ecsit [186], C8ORF38 [187], C20ORF7 [188, 189], and possibly the CIA84 ortholog PTCD1 [190], AIF [191] and IND1 [192]), one for complex II (SDHAF1 [193]), one for complex III (BCS1L [194]), six for complex IV (SURF1, COX10, COX15, SCO1, SCO2, and supposedly LRPPRC $[138,195]$ ), and four for complex V (ATP11, ATP12 [196], and possibly ATP23 [197] and OXA1L [198]). Naturally, structural proteins can have additional functions in the assembly of the particular OXPHOS complex. 
The organization of the OXPHOS system is more intricate than separately assembled complexes that are arranged in sequence in the inner mitochondrial membrane. Two models for the organization of the mitochondrial respiratory chain have been proposed: (1) the "fluid-state" or "random collision" model, which has been the preferred description, where all OXPHOS complexes diffuse individually in the membrane and electron transfer depends on the random collision of the complexes and electron carriers; (2) the "solid-state" model, which was proposed over 50 years ago and has recently received more attention, where the complexes together form large supramolecular structures termed supercomplexes or respirasomes [199, 200]. The most plausible scenario, however, is a combination of these two models: the "plasticity" model [201]. In this model, single complexes ("fluid-state" model) and different types of supercomplexes ("solid-state" model) coexist in the inner membrane. Complex I, for instance, is mainly found in association with complex III in various supercomplexes that additionally contain the electron carriers coenzyme Q and cytochrome $c$, complex IV, and sometimes complex II or $\mathrm{V}$, and are able to respire. On the other hand, most of the complexes II and IV are present as individual entities. How the supercomplexes are assembled is currently not known, but the significance of this arrangement for the stability of the different complexes is certain. This is emphasized by the finding that primary defects in, for example, complex III can lead to secondary instability of another complex, such as complex I, through improper supercomplex formation [202]. More often, though, a mutation results merely in an isolated deficiency of the particular complex. Recently, defects in Tafazzin, a protein required for the metabolism of the inner membrane phospholipid cardiolipin, was shown to affect complex $\mathrm{I} / \mathrm{III}_{2} / \mathrm{IV}$ supercomplex stability [203]. The cardiolipin deficiency resulted in weakened interactions between complexes I, III, and IV, unstable supercomplexes, and decreased levels and activities of the complexes themselves, ultimately causing Barth syndrome. Thus combined OXPHOS deficiencies can also be caused by defects in the assembly of supercomplexes.

For proper assembly of the OXPHOS system, mitochondrial fusion and fission events are crucial since they control mitochondrial morphology and thereby also mitochondrial function. Disruption of fusion or fission primarily affects two key functions of mitochondria: respiration and regulation of apoptosis [204, 205]. Defects in fusion proteins MFN2 (mitofusin 2) and OPA1 (optic atrophy 1), for instance, cause a reduction in membrane potential and OXPHOS enzyme activities and are associated with the neurodegenerative diseases Charcot-Marie-Tooth type 2A and dominant optic atrophy, respectively. Additionally, down-regulating the expression of DNML1 (dynamin 1-like, also called DRP1 or DLP1), a protein involved in mitochondrial and peroxisomal fission, led to loss of mtDNA and a decrease in mitochondrial respiration [206]. In a patient with a DNML1 deficiency, however, no mitochondrial morphology abnormalities or impairment in respiratory function could be detected, despite elevated lactate levels [206, 207].

\section{Mutations That Impair Mitochondrial Translation and Result in Mitochondrial Disorders}

Given the multitude of proteins and complexity of the processes that are required for a properly functioning OXPHOS system, it is not surprising that in many patients with a mitochondrial disorder the underlying molecular genetic defect has not yet been identified. Nonetheless, since the discovery of the first mtDNA mutations associated with mitochondrial disorders in 1988 [208, 209], numerous mutations in mtDNA and nDNA have been reported and the list is still expanding (for an overview see e.g., [43]). In each of the previous sections we have briefly mentioned the relevant genes implicated in mitochondrial disorders, with the exception of genes of the mitochondrial translation process. Here we will discuss in more detail the mutations found in this class of genes. Table 1 gives an overview of the genes implicated in combined OXPHOS deficiencies. These genes are also depicted in Figure 1.

5.1. MtDNA Mutations. As already stated in the introduction, the majority of mutations associated with combined OXPHOS deficiencies and a mitochondrial translation defect are located in the mitochondrial genome. Approximately 150 mutations, of which a large percentage awaits proper determination of their pathological significance (see [210] for a scoring system), have been reported in mitochondrial tRNA genes and a few in rRNA genes [12]. It is beyond the scope of this review to discuss these mutations in detail; overviews of mitochondrial tRNA mutations and their molecular and clinical consequences have been published before [210-212].

The tRNA ${ }^{\text {Leu(UUR) }}$ gene forms a hotspot for pathogenic mutations with nearly 30 different mutations, but in all tRNA genes, mutations have been detected now. A pathogenic tRNA gene mutation is expected to lead to a combined OXPHOS defect through a decreased rate of mitochondrial protein synthesis. The exact complexes that show a deficiency differ for each mutation, partly depending on which tRNA is affected and the percentages of the corresponding amino acid in the different OXPHOS subunits. The pathogenic mechanisms involved in the translation defect due to a tRNA mutation are numerous and frequently multiple events are involved; potential effects are: impaired transcription termination, impaired tRNA maturation, defective posttranscriptional modification of the tRNA, effect on tRNA structure (e.g., global structural weakness or conformational alteration), decreased tRNA stability (found for all mutations investigated), reduced aminoacylation, decreased binding to translation factor mtEFTu or the mitoribosome, and disturbed codon reading [211]. However, cases are known where mitochondrial translation was not or only slightly affected despite clear impairment of the OXPHOS system (e.g., [220, 221]). Possibly, this is due to toxic effects of premature translation products generated by the absence of the correctly functioning tRNA [222]. These peptides could interfere with the assembly of the OXPHOS complexes 
TABLE 1: Genes involved in the biogenesis or maintenance of multiple OXPHOS complexes and implicated in mitochondrial disorders.

\begin{tabular}{|c|c|c|c|}
\hline Affected process & Gene & Protein (function) & References \\
\hline \multicolumn{4}{|l|}{$\begin{array}{l}\text { Combined OXPHOS deficiencies with normal } \\
\text { complex II activities a }\end{array}$} \\
\hline \multirow{3}{*}{ MtDNA replication } & POLG & Polymerase $\gamma$ catalytic subunit & {$[13,213]$} \\
\hline & POLG2 & Polymerase $\gamma$ accessory subunit & {$[13,214]$} \\
\hline & C10orf2 & Twinkle (mtDNA helicase) & {$[13]$} \\
\hline \multirow{9}{*}{ Nucleotide synthesis and transport } & DGUOK & Deoxyguanosine kinase & {$[13]$} \\
\hline & TK2 & Thymidine kinase 2 & {$[13]$} \\
\hline & TYMP & $\begin{array}{l}\text { Endothelial cell growth factor } 1 \text { (thymidine } \\
\text { phosphorylase) }\end{array}$ & {$[13]$} \\
\hline & SLC25A4 & Adenine nucleotide translocator 1 & {$[13]$} \\
\hline & SLC25A3 & $\begin{array}{l}\text { Solute carrier family } 25 \text { member } 3 \text { (phosphate } \\
\text { transporter) }\end{array}$ & {$[43,215]^{\mathrm{c}}$} \\
\hline & SUCLG1 & Succinate-CoA ligase $\alpha$-subunit & {$[43,216]$} \\
\hline & SUCLA2 & Succinate-CoA ligase $\beta$-subunit & {$[13,216]$} \\
\hline & RRM2B & Ribonucleotide reductase M2 B & {$[13,217]$} \\
\hline & MPV17 & Mt inner membrane protein & [13] \\
\hline \multirow{11}{*}{ Mt translation } & 22 mitochondrial tRNA genes & & {$[12]$} \\
\hline & 2 mitochondrial rRNA genes & & {$[12]$} \\
\hline & GFM1 & Mt translation elongation factor G1 & {$[15]$} \\
\hline & TSFM & Mt translation elongation factor Ts & {$[21]$} \\
\hline & TUFM & Mt translation elongation factor $\mathrm{Tu}$ & {$[22]$} \\
\hline & MRPS16 & Mt ribosomal protein S16 & {$[18]$} \\
\hline & MRPS22 & Mt ribosomal protein S22 & {$[19]$} \\
\hline & PUS1 & Pseudouridine synthase 1 & {$[14]$} \\
\hline & TRMU & $\begin{array}{l}\text { tRNA 5-methylaminomethyl-2-thiouridylate } \\
\text { methyltransferase }\end{array}$ & {$[24]$} \\
\hline & DARS2 & Mt aspartyl-tRNA synthetase 2 & {$[20]^{\mathrm{c}}$} \\
\hline & RARS2 & Mt arginyl-tRNA synthetase 2 & {$[16]$} \\
\hline \multicolumn{4}{|l|}{ Other combined OXPHOS deficiencies ${ }^{b}$} \\
\hline \multirow[t]{2}{*}{ Mt protein import } & TIMM8A & $\begin{array}{l}\text { Translocase of inner mt membrane } 8 \text { homolog } \\
\text { A (small TIM complex subunit) }\end{array}$ & {$[74]^{\mathrm{c}}$} \\
\hline & DNAJC19 & $\begin{array}{l}\text { DnaJ homolog, subfamily C, member } 19 \\
\text { (TIM23 complex subunit) }\end{array}$ & {$[76]$} \\
\hline \multirow{4}{*}{ Mt membrane biogenesis and maintenance } & TAZ & Tafazzin (cardiolipin metabolism) & {$[203,218]$} \\
\hline & OPA1 & Optic atrophy 1 (mt fusion) & {$[205]$} \\
\hline & MFN2 & Mitofusin 2 (mt fusion) & {$[205]$} \\
\hline & DNM1L & Dynamin 1-like (mt and peroxisomal fission) & {$[207]^{\mathrm{c}}$} \\
\hline Mt protein processing and quality control & SPG7 & $\begin{array}{l}\text { Spastic paraplegia } 7 \text { or paraplegin (m-AAA } \\
\text { protease subunit) }\end{array}$ & {$[144,219]$} \\
\hline
\end{tabular}

${ }^{\mathrm{a}}$ Based on the function of the affected proteins, a combined complex I, III, IV and V deficiency would be expected, however, not always do all these enzyme complexes display decreased activities.

${ }^{b}$ All OXPHOS complexes are expected to malfunction based on the function of the affected proteins; nonetheless, large variations have been found in the exact OXPHOS complexes involved.

${ }^{\mathrm{c}}$ The OXPHOS complexes showed normal activities.

or exert their toxic effect through interactions with other (non)mitochondrial components, while a quantitative deficit in mitochondrial protein synthesis cannot be detected.

The best-studied mitochondrial tRNA mutations are $3243 \mathrm{~A}>\mathrm{G}$ in tRNA ${ }^{\mathrm{Leu}(\mathrm{UUR})}(\mathrm{MT}-\mathrm{TL} 1)$ and $8344 \mathrm{~A}>\mathrm{G}$ in
tRNA $^{\text {Lys }}(M T-T K)$. The $3243 \mathrm{~A}>\mathrm{G}$ mutation is one of the most common mutations and causes a range of clinical phenotypes, of which MELAS is the most prevalent [223]. There is controversy over the pathogenic mechanism of the $3243 \mathrm{~A}>\mathrm{G}$ mutation: both loss-of-function (due to poor 
aminoacylation, reduced stability or lack of wobble-base $U$ hypermodification) and gain-of-function (due to lack of the hypermodification) of the mutant tRNA have been proposed [224]. The post-transcriptional taurine modification at the anticodon wobble position is needed to restrict decoding to leucine UUR codons. Loss of this modification leads to varying degrees of mitochondrial translation malfunctioning in different cellular backgrounds through a combination of a decoding defect of UUG (and UUA) codons (lossof-function) and amino acid misincorporation (gain-offunction) $[126,225]$. Additionally, the $3243 \mathrm{~A}>\mathrm{G}$ mutation was shown to diminish $16 \mathrm{~S}$ rRNA transcription termination and alter processing of the primary transcript $[61,226]$, but these effects are likely to contribute less to the disease etiology than the previously mentioned mechanisms. The $8344 \mathrm{~A}>\mathrm{G}$ mutation is associated with MERRF (myoclonic epilepsy with ragged-red fibers). It has also been reported to affect aminoacylation and taurine modification of the wobble-base $\mathrm{U}$, the latter which abolishes codon-anticodon pairing on the mitoribosomes for both tRNA ${ }^{\text {Lys }}$ codons [225, 227]. This generates a marked decrease in mitochondrial protein synthesis that is most pronounced in proteins with a high lysine content and is believed to result from premature translation termination.

Most rRNA mutations have been reported in the $12 \mathrm{~S}$ rRNA gene (MT-RNR1) and all of these are associated with nonsyndromic sensorineural hearing loss or aminoglycoside-induced deafness, with the 1555A $>$ G mutation forming one of the most common causes [12, 228]. This mutation is located in the decoding site of the mitoribosomal SSU and results in a secondary rRNA structure that more closely resembles the corresponding region of the bacterial 16S rRNA, impairing mitochondrial protein synthesis and facilitating interaction with aminoglycoside antibiotics, which again exacerbates the translation defect. The mutation alone does not lead to disease, only in combination with modulators such as the aminoglycosides, mitochondrial haplotypes and nuclear modifier genes (e.g., TFB1M, as already mentioned in Section 3.3). In the $16 \mathrm{~S}$ rRNA gene (MT-RNR2) merely 3 mutations have been found: $2835 \mathrm{C}>\mathrm{T}, 3093 \mathrm{C}>\mathrm{G}$, and 3196G $>\mathrm{A}$ [12]. These mutations are thought to be associated with Rett syndrome, MELAS, and Alzheimer and Parkinson disease, respectively, [229-231]. Nevertheless, further investigations are necessary to determine their pathogenicity.

5.2. nDNA Mutations. Up till now, mutations in nine nuclear genes implicated in mitochondrial protein synthesis have been associated with mitochondrial disorders. The first report was a homozygous missense mutation in the tRNA modifying gene PUS1 [14], and shortly thereafter homozygous mutations were detected in the genes for elongation factor mtEFG1 [15] and mitoribosomal protein MRPS16 [18]. Subsequently, four compound heterozygous mutations in GFM1 (coding for mtEFG1) [22, 25] and homozygous mutations in TUFM (encoding mtEFTu) [22], TSFM (coding for mtEFTs) [21], MRPS22 [19], PUS1 again [17], and in the arginine tRNA synthetase gene (RARS2) [16] were found, bringing the total number of mutations on
12. Additionally, several compound heterozygous mutations have been reported in the gene for mitochondrial aspartyltRNA synthetase (DARS2) [20, 23]. Recently, 9 mutations were identified in the gene for another tRNA modifying gene, TRMU [24]. All patients harboring these mutations show combined OXPHOS deficiencies, with (near) normal complex II activities, and a clear defect in mitochondrial translation (the latter was not tested for the MRPS22, RARS2, and DARS2 mutations). The one exception is DARS2: surprisingly, Blue-native PAGE as well as spectrophotometric measurements revealed normal OXPHOS enzyme activities [20]. The clinical features differ substantially between all patients and even between patients that carry the same mutation, but generally the mutations result in severe and early-fatal diseases.

As already mentioned in Section 2.3, defects in the tRNAmodifying enzymes PUS1 and TRMU can result in mitochondrial disease. PUS1 converts uridine into pseudouridine at several cytoplasmic and mitochondrial tRNA positions and thereby improves translation efficiency in the cytosol as well as the mitochondrion [17]. Thus it is not part of the translation machinery, but it is required for protein synthesis due to its function in post-transcriptional modification of tRNAs. Pseudouridylation is the most frequently found modification in tRNAs [232], however, the exact function is not entirely clear. The marked variability in the severity of the MLASA syndrome, despite the presence of an identical PUS1 mutation, could partly be explained by the dual localization of PUS1 [17]. A defect in PUS1 therefore impairs both cytosolic and mitochondrial translation, resulting in corresponding clinical symptoms that can vary due to individual differences in compensation mechanisms in both cell compartments. Bykhovskaya et al. suggested that compensatory changes in transcript levels of ribosomal proteins can overcome the lack of pseudouridylation of tRNAs and that pleiotropic effects of PUS1 on non-tRNA substrates involved in transcription and iron metabolism are a major cause of the disease phenotype [233]. Notably, complex II can be affected slightly in addition to the other OXPHOS complexes that all contain mtDNA-encoded subunits [17]. This could be a primary effect of the decrease in cytosolic translation or it could be a secondary effect of the mitochondrial translation deficit, leading to disruption of the mtDNA-dependent complexes, which can subsequently cause destabilization of the entire OXPHOS system. TRMU (tRNA 5-methylaminomethyl-2thiouridylate methyltransferase) is responsible for the 2thio modification of the wobble-base of the mitochondrial $\mathrm{tRNA}^{\mathrm{Lys}}, \mathrm{tRNA}^{\mathrm{Gln}}$ and $\mathrm{tRNA}^{\mathrm{Glu}}$. Defects in this enzyme result in reduced steady-state levels of these three tRNAs and consequently impaired mitochondrial protein synthesis $[24,62]$. The 2-thiouridylation is reported to be critical for effective codon-anticodon interaction and ribosome binding $[234,235]$.

Concerning the mitochondrial translation factors, defects have only been found in proteins involved in the elongation phase, in all elongation factors except for mtEFG2, which appears to function in termination instead elongation. In GFM1, mutations have been reported in nearly all protein domains, leading to severe hepato(encephalo)pathy 
$[15,22,25]$. All mutations result in a marked global translation defect, with the strongest deficit in the three complex IV subunits and the two complex I subunits ND5 and ND6. Both subunits of complex V (ATP6 and ATP8) show normal or even increased synthesis rates, possibly caused by more efficient protein synthesis of bicistronic compared to monocistronic mRNAs, which would then also explain the near normal mitochondrial translation levels of ND4 and ND4L. This variable pattern in translation impairment was also found for a mutation in TSFM [21], which will be described below. Surprisingly, tissues are selectively affected by GFM1 mutations, in spite of its ubiquitous expression, with liver being most severely affected and heart hardly showing a defect [25]. This tissue specificity appears to result from differences among tissues in the relative ratios of the elongation factors and in adaptive changes herein in response to dysfunction. For example, transcription of TUFM was upregulated in cardiac tissue in patients with a GFM1 mutation and overexpression of either TUFM or TSFM in control and patient fibroblasts impaired mitochondrial translation. Overexpression of GFM2, on the contrary, did not have a clear effect on protein synthesis in either control or patient cells $[15,25]$. Remarkably, mtEFTu or mtEFG2, but not mtEFTs or mtEFG1, can partially suppress the combined OXPHOS system defect caused by the $3243 \mathrm{~A}>\mathrm{G}$ mutation in tRNA $^{\mathrm{Leu}(\mathrm{UUR})}$ [126]. These observations evidence that efficient mitochondrial translation partly depends on appropriate ratios of the elongation factors. A homozygous mutation in TUFM was shown to be responsible for rapidly progressive encephalopathy [22]. The mutation, located in the tRNA-binding region of mtEFTu, hampers the formation of the ternary complex with GTP and an aminoacylated tRNA, resulting in a severe decrease in mitochondrial protein synthesis $[22,236]$. Notably, a homozygous mutation in TSFM led to encephalomyopathy in one patient and hypertrophic cardiomyopathy in another [21]. This could be due to individual differences in relative abundance of the translation factors and compensatory mechanisms in the various tissues. Alternatively, as yet unknown genetic modifiers of the mitochondrial translation machinery could be involved. Steady-state levels of not only mtEFTs but also mtEFTu were reduced, and overexpression of either factor rescued the OXPHOS deficiency and translation defect. The most likely explanation for these findings is that the mutation, situated in a subdomain of mtEFTs that interacts with mtEFTu, destabilizes the mtEFTu-mtEFTs complex and promotes turnover of its components. Additional mtEFTu or mtEFTs would then stabilize the complex.

Of all 81 human MRPs, mutations have been found in merely two of them: MRPS16 and MRPS22 [18, 19]. Both defects resulted in a marked decrease in the $12 \mathrm{~S}$ rRNA transcript level, probably caused by impaired assembly of the mitoribosomal small subunit, generating unincorporated and instable $12 \mathrm{~S}$ rRNA. MRPS16 is evolutionary highly conserved, however, MRPS22 is only present in metazoa [107]. Recently, both proteins were shown to be important for assembly of the SSU [123]. In fibroblasts from patients with a MRPS16 or MRPS22 mutation, the level of MRPS11 was significantly reduced, whereas considerable amounts of MRPS2 were present. Furthermore, MRPS16 was barely detectable in the MRPS22-mutated patient. The presence of MRPS22 was not determined in these patients. On the other hand, near normal levels of MRPL13, MRPL15 [123] as well as $16 \mathrm{~S}$ rRNA $[18,19]$ were found. These observations indicate that both MRPS16 and MRPS22 are essential for assembly and stability of the SSU. A lack of these MRPs results in the failure to assemble part of the mitoribosome, containing at least MRPS11, MRPS16, MRPS22, and 12S rRNA, and subsequent degradation of its components. Both a macromolecular complex containing MRPS2 and the mitoribosomal large subunit can still be formed in the absence of a functional SSU, suggesting that the assembly of the mitoribosome is a process consisting of relatively independent subassembly steps.

Mutations in the mitochondrial arginyl- and aspartyltRNA synthetases (RARS2 and DARS2) are associated with severe encephalopathy with pontocerebellar hypoplasia and LBSL (leukoencephalopathy with brain stem and spinal cord involvement and lactate elevation), respectively [16, 20, 23]. In both genes, intronic mutations that affect splicing were detected. The absence of extracerebral symptoms might be explained by a potential difference in abundance of splicing factors between brain and the unaffected tissues, enabling synthesis of small amounts of wild-type transcript of the synthetases in most tissues. Alternatively, the vulnerability of the brain for aminoacyl-tRNA synthetase defects could be due to the high expression of mitochondrial tRNAs in this tissue [237]. The tRNA ${ }^{\mathrm{Arg}}$ transcript is scarcely present, but almost fully acylated, in patient fibroblasts harboring a RARS2 mutation. Presumably, the little available wild-type RARS2 can aminoacylate a small portion of the tRNA ${ }^{\text {Arg }}$ molecules and the uncharged transcripts then become unstable. This will impair mitochondrial protein synthesis, which has only been confirmed in yeast [238]. In contrast, DARS2 mutations do not seem to affect mitochondrial translation and likewise do not result in defects of the OXPHOS complexes, notwithstanding a clear reduction in aminoacylation activity [20]. The reason for this is currently not understood.

Besides these nine gene products, numerous proteins are indirectly involved in mitochondrial translation, as should be evident from the current review, and defects in these proteins could undoubtedly also interfere with the translation process. For example, lack of the protease paraplegin (see Section 3.3 for information on its function) results in impaired mitochondrial translation in yeast and in a hereditary spastic paraplegia (HSP) mouse model [143]. Nonetheless, HSP patients with mutations in paraplegin (HSP7) do not show consistent OXPHOS enzyme deficiencies [239-241]; often only or mainly complex I is affected, while a combined defect would be expected. The selective involvement of certain neurons could in this case be rationalized by tissue-specific differences in the expression of m-AAA protease subunits and their assembly into proteolytic complexes, which vary in their subunit composition depending on subunit availability [242]. This 
is analogous to the importance of elongation factor ratios for efficient mitochondrial translation and tissue-specific variability herein.

\section{Future Prospects}

We have provided an extensive overview of the proteins and processes (in)directly involved in mitochondrial translation and the biogenesis of the OXPHOS system. Even though our understanding of the mechanisms implicated in mitochondrial disease has increased rapidly over the last two decades, it is far from complete. Due to the multitude of proteins and intricacy of the processes needed for a properly functioning OXPHOS system, identifying the genetic defect that underlies an OXPHOS deficiency is not an easy task. The shortage of large or consanguineous families as well as the substantial clinical and genetic heterogeneity of mitochondrial disorders complicate the search by limiting the available strategies. For instance, techniques such as linkage analysis and homozygosity mapping that form powerful tools in combination with whole-genome experimental data sets [136, 243] often cannot be applied and mutation chips are currently only available for the mtDNA. Consequently, the molecular basis of many OXPHOS disorders remains unresolved. In the future, molecular genetic diagnosis of patients suspected to suffer from a mitochondrial disorder might no longer require extensive investigations that integrate information from clinical phenotype, family history, brain imaging and laboratory findings to direct the laborious tasks of screening known candidate genes and, when this is unsuccessful, searching for new genetic causes [43]. Instead, recent progress in the development of next-generation DNA sequencing technologies, which are much cheaper and faster than the conventional approach of polymerase chain reaction followed by capillary sequencing, indicates that within the next few decades high-throughput sequencing could become a feasible option for mutation detection [244, 245]. These methods are anticipated to eventually enable sequencing of the entire human genome for under $\$ 1000$ within a day, allowing their routine clinical use and accelerating the discovery of novel disease genes. Exome sequencing, that is, the targeted sequencing of all protein-coding regions, offers an alternative to whole-genome sequencing by facilitating direct identification of the causative gene at a fraction of the costs [246, 247]. However, much remains to be achieved, for example proper bioinformatic tools to deal with the tremendous amounts of data, before such technologies can be readily applied to elucidate the genetic etiology of OXPHOS deficiencies and other disorders. Systems biology techniques will keep increasing our knowledge of the mechanisms underlying complex diseases and in combination with high-throughput sequencing these approaches will advance disease-gene discovery even more. Integrative analysis of functional data is useful especially for gaining insight into the scarcely understood field of modifier genes, which are thought to account for part of the clinical variability seen in mitochondrial diseases. Systematic mapping of genetic interactions revealed a class of modifier or "hub" genes that are proposed to enhance the phenotypic consequences of mutations in many different genes, the "specifier" genes that define the specific disorders, and thus serve as global modifier genes in multiple mechanistically unrelated disorders [248]. Hopefully, these and other important findings will lead to the discovery of additional modifier genes implicated in mitochondrial disorders. Progress in mutation detection, both in specifier and modifier genes, is crucial for extending the possibilities for genetic counseling, prenatal diagnosis, and interventions to prevent transmission now and to cure these serious disorders in the future. Currently, no effective therapy is available; the various existing treatment strategies are mainly supportive $[249,250]$. Gene therapy might offer a solution since it allows for curative treatment without the need for a clear genotype-phenotype correlation, which is often lacking in mitochondrial disorders. Although the development is still in its infancy for both mtDNA and nDNA gene therapy and many challenges are to be overcome, promising results have been obtained in cell cultures and animal models, providing hope for a cure in the not-toodistant future. Thus rapid advances in technologies and consequently in our understanding of the pathogenesis of OXPHOS defects should lead to the ultimate goal of effectively preventing and curing these often devastating disorders.

\section{Acknowledgment}

This work was supported by the European Union's Sixth Framework Program, contract number LSHMCT-2004005260 (MITOCIRCLE).

\section{References}

[1] M. W. Gray, G. Burger, and B. F. Lang, "Mitochondrial evolution," Science, vol. 283, no. 5407, pp. 1476-1481, 1999.

[2] K.-D. Gerbitz, K. Gempel, and D. Brdiczka, "Mitochondria and diabetes: genetic, biochemical, and clinical implications of the cellular energy circuit," Diabetes, vol. 45, no. 2, pp. 113126, 1996.

[3] K. Hojlund, M. Mogensen, K. Sahlin, and H. Beck-Nielsen, "Mitochondrial dysfunction in type 2 diabetes and obesity," Endocrinology and Metabolism Clinics of North America, vol. 37, no. 3, pp. 713-731, 2008.

[4] W. Mandemakers, V. A. Morais, and B. De Strooper, "A cell biological perspective on mitochondrial dysfunction in Parkinson disease and other neurodegenerative diseases," Journal of Cell Science, vol. 120, no. 10, pp. 1707-1716, 2007.

[5] D. C. Chan, "Mitochondria: dynamic organelles in disease, aging, and development," Cell, vol. 125, no. 7, pp. 1241-1252, 2006.

[6] L. Guarente, "Mitochondria-a nexus for aging, calorie restriction, and sirtuins?" Cell, vol. 132, no. 2, pp. 171-176, 2008.

[7] A. M. Schaefer, R. W. Taylor, D. M. Turnbull, and P. F. Chinnery, "The epidemiology of mitochondrial disorderspast, present and future," Biochimica et Biophysica Acta, vol. 1659, no. 2-3, pp. 115-120, 2004.

[8] M. Saraste, "Oxidative phosphorylation at the fin de siecle," Science, vol. 283, no. 5407, pp. 1488-1493, 1999.

[9] J. L. C. M. Loeffen, J. A. M. Smeitink, J. M. F. Trijbels, et al., "Isolated complex I deficiency in children: clinical, 
biochemical and genetic aspects," Human Mutation, vol. 15, no. 2, pp. 123-134, 2000.

[10] F.-G. Debray, M. Lambert, and G. A. Mitchell, "Disorders of mitochondrial function," Current Opinion in Pediatrics, vol. 20, no. 4, pp. 471-482, 2008.

[11] M. Zeviani and S. Di Donato, "Mitochondrial disorders," Brain, vol. 127, no. 10, pp. 2153-2172, 2004.

[12] "MITOMAP: A Human Mitochondrial Genome Database," 2009, http://www.mitomap.org/MITOMAP.

[13] W. C. Copeland, "Inherited mitochondrial diseases of DNA replication," Annual Review of Medicine, vol. 59, pp. 131-146, 2008.

[14] Y. Bykhovskaya, K. Casas, E. Mengesha, A. Inbal, and N. Fischel-Ghodsian, "Missense mutation in pseudouridine synthase 1 (PUS1) causes mitochondrial myopathy and sideroblastic anemia (MLASA)," American Journal of Human Genetics, vol. 74, no. 6, pp. 1303-1308, 2004.

[15] M. J. H. Coenen, H. Antonicka, C. Ugalde, et al., "Mutant mitochondrial elongation factor G1 and combined oxidative phosphorylation deficiency," New England Journal of Medicine, vol. 351, no. 20, pp. 2080-2086, 2004.

[16] S. Edvardson, A. Shaag, O. Kolesnikova, et al., "Deleterious mutation in the mitochondrial arginyl-transfer RNA synthetase gene is associated with pontocerebellar hypoplasia," American Journal of Human Genetics, vol. 81, no. 4, pp. 857862, 2007.

[17] E. Fernandez-Vizarra, A. Berardinelli, L. Valente, V. Tiranti, and M. Zeviani, "Nonsense mutation in pseudouridylate synthase 1 (PUS1) in two brothers affected by myopathy, lactic acidosis and sideroblastic anaemia (MLASA)," Journal of Medical Genetics, vol. 44, no. 3, pp. 173-180, 2007.

[18] C. Miller, A. Saada, N. Shaul, et al., "Defective mitochondrial translation caused by a ribosomal protein (MRPS16) mutation," Annals of Neurology, vol. 56, no. 5, pp. 734-738, 2004.

[19] A. Saada, A. Shaag, S. Arnon, et al., "Antenatal mitochondrial disease caused by mitochondrial ribosomal protein (MRPS22) mutation," Journal of Medical Genetics, vol. 44, no. 12, pp. 784-786, 2007.

[20] G. C. Scheper, T. van der Klok, R. J. van Andel, et al., "Mitochondrial aspartyl-tRNA synthetase deficiency causes leukoencephalopathy with brain stem and spinal cord involvement and lactate elevation," Nature Genetics, vol. 39, no. 4, pp. 534-539, 2007.

[21] J. A. M. Smeitink, O. Elpeleg, H. Antonicka, et al., "Distinct clinical phenotypes associated with a mutation in the mitochondrial translation elongation factor EFTs," American Journal of Human Genetics, vol. 79, no. 5, pp. 869-877, 2006.

[22] L. Valente, V. Tiranti, R. M. Marsano, et al., "Infantile encephalopathy and defective mitochondrial DNA translation in patients with mutations of mitochondrial elongation factors EFG1 and EFTu," American Journal of Human Genetics, vol. 80, no. 1, pp. 44-58, 2007.

[23] P. Isohanni, T. Linnankivi, J. Buzkova, et al., "DARS2 mutations in mitochondrial leucoencephalopathy and multiple sclerosis," Journal of Medical Genetics, vol. 47, no. 1, pp. 6670, 2010.

[24] A. Zeharia, A. Shaag, O. Pappo, et al., "Acute infantile liver failure due to mutations in the TRMU gene," American Journal of Human Genetics, vol. 85, no. 3, pp. 401-407, 2009.

[25] H. Antonicka, F. Sasarman, N. G. Kennaway, and E. A. Shoubridge, "The molecular basis for tissue specificity of the oxidative phosphorylation deficiencies in patients with mutations in the mitochondrial translation factor EFG1,"
Human Molecular Genetics, vol. 15, no. 11, pp. 1835-1846, 2006.

[26] S. Anderson, A. T. Bankier, and B. G. Barrell, "Sequence and organization of the human mitochondrial genome," Nature, vol. 290 , no. 5806 , pp. 457-465, 1981.

[27] W. M. Brown, M. George Jr., and A. C. Wilson, "Rapid evolution of animal mitochondrial DNA," Proceedings of the National Academy of Sciences of the United States of America, vol. 76, no. 4, pp. 1967-1971, 1979.

[28] M. Lynch, B. Koskella, and S. Schaack, "Mutation pressure and the evolution of organelle genomic architecture," Science, vol. 311, no. 5768, pp. 1727-1730, 2006.

[29] C. Richter, J.-W. Park, and B. N. Ames, "Normal oxidative damage to mitochondrial and nuclear DNA is extensive," Proceedings of the National Academy of Sciences of the United States of America, vol. 85, no. 17, pp. 6465-6467, 1988.

[30] R. W. Taylor and D. M. Turnbull, "Mitochondrial DNA mutations in human disease," Nature Reviews Genetics, vol. 6, no. 5, pp. 389-402, 2005.

[31] D. Bogenhagen and D. A. Clayton, "Mouse 1 cell mitochondrial DNA molecules are selected randomly for replication throughout the cell cycle," Cell, vol. 11, no. 4, pp. 719-727, 1977.

[32] D. A. Clayton, "Replication of animal mitochondrial DNA," Cell, vol. 28, no. 4, pp. 693-705, 1982.

[33] G. S. Shadel and D. A. Clayton, "Mitochondrial DNA maintenance in vertebrates," Annual Review of Biochemistry, vol. 66, pp. 409-436, 1997.

[34] I. J. Holt, H. E. Lorimer, and H. T. Jacobs, "Coupled leadingand lagging-strand synthesis of mammalian mitochondrial DNA," Cell, vol. 100, no. 5, pp. 515-524, 2000.

[35] T. Yasukawa, M.-Y. Yang, H. T. Jacobs, and I. J. Holt, "A bidirectional origin of replication maps to the major noncoding region of human mitochondrial DNA," Molecular Cell, vol. 18, no. 6, pp. 651-662, 2005.

[36] M. A. Graziewicz, M. J. Longley, and W. C. Copeland, "DNA polymerase $\gamma$ in mitochondrial DNA replication and repair," Chemical Reviews, vol. 106, no. 2, pp. 383-405, 2006.

[37] I. J. Holt, J. He, C.-C. Mao, et al., "Mammalian mitochondrial nucleoids: organizing an independently minded genome," Mitochondrion, vol. 7, no. 5, pp. 311-321, 2007.

[38] F. Malka, A. Lombès, and M. Rojo, "Organization, dynamics and transmission of mitochondrial DNA: focus on vertebrate nucleoids," Biochimica et Biophysica Acta, vol. 1763, no. 5-6, pp. 463-472, 2006.

[39] N. B. Larsen, M. Rasmussen, and L. J. Rasmussen, "Nuclear and mitochondrial DNA repair: similar pathways?" Mitochondrion, vol. 5, no. 2, pp. 89-108, 2005.

[40] J. A. Stuart and M. F. Brown, "Mitochondrial DNA maintenance and bioenergetics," Biochimica et Biophysica Acta, vol. 1757, no. 2, pp. 79-89, 2006.

[41] A. Saada, "Deoxyribonucleotides and disorders of mitochondrial DNA integrity," DNA and Cell Biology, vol. 23, no. 12, pp. 797-806, 2004.

[42] A. Spinazzola and M. Zeviani, "Disorders of nuclearmitochondrial intergenomic signaling," Gene, vol. 354, no. 1-2, pp. 162-168, 2005.

[43] D. M. Kirby and D. R. Thorburn, "Approaches to finding the molecular basis of mitochondrial oxidative phosphorylation disorders," Twin Research and Human Genetics, vol. 11, no. 4, pp. 395-411, 2008.

[44] N. D. Bonawitz, D. A. Clayton, and G. S. Shadel, "Initiation and beyond: multiple functions of the human mitochondrial 
transcription machinery," Molecular Cell, vol. 24, no. 6, pp. 813-825, 2006.

[45] M. Falkenberg, N.-G. Larsson, and C. M. Gustafsson, "DNA replication and transcription in mammalian mitochondria," Annual Review of Biochemistry, vol. 76, pp. 679-699, 2007.

[46] M. Roberti, P. L. Polosa, F. Bruni, et al., "The MTERF family proteins: mitochondrial transcription regulators and beyond," Biochimica et Biophysica Acta, vol. 1787, no. 5, pp. 303-311, 2009.

[47] A. K. Hyvärinen, J. L. O. Pohjoismäki, A. Reyes, et al., "The mitochondrial transcription termination factor mTERF modulates replication pausing in human mitochondrial DNA," Nucleic Acids Research, vol. 35, no. 19, pp. 6458-6474, 2007.

[48] T. Linder, C. B. Park, J. Asin-Cayuela, et al., "A family of putative transcription termination factors shared amongst metazoans and plants," Current Genetics, vol. 48, no. 4, pp. 265-269, 2005.

[49] Y. Chen, G. Zhou, M. Yu, et al., "Cloning and functional analysis of human mTERFL encoding a novel mitochondrial transcription termination factor-like protein," Biochemical and Biophysical Research Communications, vol. 337, no. 4, pp. 1112-1118, 2005.

[50] M. Pellegrini, J. Asin-Cayuela, H. Erdjument-Bromage, P. Tempst, N.-G. Larsson, and C. M. Gustafsson, "MTERF2 is a nucleoid component in mammalian mitochondria," Biochimica et Biophysica Acta, vol. 1787, no. 5, pp. 296-302, 2009.

[51] T. Wenz, C. Luca, A. Torraco, and C. T. Moraes, "mTERF2 regulates oxidative phosphorylation by modulating mtDNA transcription," Cell Metabolism, vol. 9, no. 6, pp. 499-511, 2009.

[52] C. B. Park, J. Asin-Cayuela, Y. Cámara, et al., "MTERF3 is a negative regulator of mammalian mtDNA transcription," Cell, vol. 130, no. 2, pp. 273-285, 2007.

[53] M. Roberti, F. Bruni, P. Loguercio Polosa, C. Manzari, M. N. Gadaleta, and P. Cantatore, "MTERF3, the most conserved member of the mTERF-family, is a modular factor involved in mitochondrial protein synthesis," Biochimica et Biophysica Acta, vol. 1757, no. 9-10, pp. 1199-1206, 2006.

[54] A. Cayuela, Y. Shi, and C. M. Gustafsson, "Initial characterization of MTERF4, a paralogue of MTERF1 (mTERF)," in Proceedings of the 7th European Meeting on Mitochondrial Pathology (EUROMIT '08), p. 20, Stockholm, Sweden, June 2008, abstract no. 14 .

[55] D. Ojala, J. Montoya, and G. Attardi, "tRNA punctuation model of RNA processing in human mitochondria," Nature, vol. 290, no. 5806, pp. 470-474, 1981.

[56] J. Montoya, M. J. López-Pérez, and E. Ruiz-Pesini, "Mitochondrial DNA transcription and diseases: past, present and future," Biochimica et Biophysica Acta, vol. 1757, no. 9-10, pp. 1179-1189, 2006.

[57] D. Gagliardi, P. P. Stepien, R. J. Temperley, R. N. Lightowlers, and Z. M. A. Chrzanowska-Lightowlers, "Messenger RNA stability in mitochondria: different means to an end," Trends in Genetics, vol. 20, no. 6, pp. 260-267, 2004.

[58] H.-W. Chen, C. M. Koehler, and M. A. Teitell, "Human polynucleotide phosphorylase: location matters," Trends in Cell Biology, vol. 17, no. 12, pp. 600-608, 2007.

[59] L. Khidr, G. Wu, A. Davila, V. Procaccio, D. Wallace, and W.H. Lee, "Role of SUV3 helicase in maintaining mitochondrial homeostasis in human cells," Journal of Biological Chemistry, vol. 283, no. 40, pp. 27064-27073, 2008.
[60] A. Chomyn, A. Martinuzzi, M. Yoneda, et al., "MELAS mutation in mtDNA binding site for transcription termination factor causes defects in protein synthesis and in respiration but no change in levels of upstream and downstream mature transcripts," Proceedings of the National Academy of Sciences of the United States of America, vol. 89, no. 10, pp. 4221-4225, 1992.

[61] J. F. Hess, M. A. Parisi, J. L. Bennett, and D. A. Clayton, "Impairment of mitochondrial transcription termination by a point mutation associated with the MELAS subgroup of mitochondrial encephalomyopathies," Nature, vol. 351, no. 6323, pp. 236-239, 1991.

[62] M.-X. Guan, Q. Yan, X. Li, et al., "Mutation in TRMU related to transfer RNA modification modulates the phenotypic expression of the deafness-associated mitochondrial $12 \mathrm{~S}$ ribosomal RNA mutations," American Journal of Human Genetics, vol. 79, no. 2, pp. 291-302, 2006.

[63] C. Knox, E. Sass, W. Neupert, and O. Pines, "Import into mitochondria, folding and retrograde movement of fumarase in yeast," Journal of Biological Chemistry, vol. 273, no. 40, pp. 25587-25593, 1998.

[64] J. A. MacKenzie and R. M. Payne, "Ribosomes specifically bind to mammalian mitochondria via protease-sensitive proteins on the outer membrane," Journal of Biological Chemistry, vol. 279, no. 11, pp. 9803-9810, 2004.

[65] K. Verner, "Co-translational protein import into mitochondria: an alternative view," Trends in Biochemical Sciences, vol. 18, no. 10, pp. 366-371, 1993.

[66] P. Marc, A. Margeot, F. Devaux, C. Blugeon, M. CorralDebrinski, and C. Jacq, "Genome-wide analysis of mRNAs targeted to yeast mitochondria," EMBO Reports, vol. 3, no. 2, pp. 159-164, 2002.

[67] A. Mukhopadhyay, L. Ni, and H. Weiner, "A co-translational model to explain the in vivo import of proteins into HeLa cell mitochondria," Biochemical Journal, vol. 382, no. 1, pp. 385-392, 2004.

[68] M. Garcia, X. Darzacq, T. Delaveau, L. Jourdren, R. H. Singer, and C. Jacq, "Mitochondria-associated yeast mRNAs and the biogenesis of molecular complexes," Molecular Biology of the Cell, vol. 18, no. 2, pp. 362-368, 2007.

[69] A. Margeot, M. Garcia, W. Wang, E. Tetaud, J. P. di Rago, and C. Jacq, "Why are many mRNAs translated to the vicinity of mitochondria: a role in protein complex assembly?" Gene, vol. 354, no. 1-2, pp. 64-71, 2005.

[70] F. J. Iborra, H. Kimura, and P. R. Cook, "The functional organization of mitochondrial genomes in human cells," BMC Biology, vol. 2, article 9, 2004.

[71] W. Neupert and J. M. Herrmann, "Translocation of proteins into mitochondria," Annual Review of Biochemistry, vol. 76, pp. 723-749, 2007.

[72] N. Wiedemann, A. E. Frazier, and N. Pfanner, "The protein import machinery of mitochondria," Journal of Biological Chemistry, vol. 279, no. 15, pp. 14473-14476, 2004.

[73] J. R. Blesa, A. Solano, P. Briones, J. A. Prieto-Ruiz, J. Hernández-Yago, and F. Coria, "Molecular genetics of a patient with Mohr-Tranebjaerg syndrome due to a new mutation in the DDP1 gene," NeuroMolecular Medicine, vol. 9, no. 4, pp. 285-291, 2007.

[74] K. Roesch, S. P. Curran, L. Tranebjaerg, and C. M. Koehler, "Human deafness dystonia syndrome is caused by a defect in assembly of the DDP1/TIMM8a-TIMM13 complex," Human Molecular Genetics, vol. 11, no. 5, pp. 477-486, 2002.

[75] J. Binder, S. Hofmann, S. Kreisel, et al., "Clinical and molecular findings in a patient with a novel mutation in the 
deafness-dystonia peptide (DDP1) gene," Brain, vol. 126, no. 8, pp. 1814-1820, 2003.

[76] K. M. Davey, J. S. Parboosingh, D. R. McLeod, et al., "Mutation of DNAJC19, a human homologue of yeast inner mitochondrial membrane co-chaperones, causes DCMA syndrome, a novel autosomal recessive Barth syndrome-like condition," Journal of Medical Genetics, vol. 43, no. 5, pp. 385-393, 2006.

[77] D. Mokranjac, M. Sichting, W. Neupert, and K. Hell, “Tim14, a novel key component of the import motor of the TIM23 protein translocase of mitochondria," EMBO Journal, vol. 22, no. 19, pp. 4945-4956, 2003.

[78] X. Pérez-Martínez, S. Funes, Y. Camacho-Villasana, S. Marjavaara, F. Tavares-Carreón, and M. Shingú-Vázquez, "Protein synthesis and assembly in mitochondrial disorders," Current Topics in Medicinal Chemistry, vol. 8, no. 15, pp. 1335-1350, 2008.

[79] S. Osawa, T. H. Jukes, K. Watanabe, and A. Muto, "Recent evidence for evolution of the genetic code," Microbiological Reviews, vol. 56, no. 1, pp. 229-264, 1992.

[80] J. Montoya, D. Ojala, and G. Attardi, "Distinctive features of the $5^{\prime}$-terminal sequences of the human mitochondrial mRNAs," Nature, vol. 290, no. 5806, pp. 465-470, 1981.

[81] K. Grohmann, F. Amalric, S. Crews, and G. Attardi, "Failure to detect "cap" structures in mitochondrial DNA-coded poly(A)-containing RNA from HeLa cells," Nucleic Acids Research, vol. 5, no. 3, pp. 637-651, 1978.

[82] H.-X. Liao and L. L. Spremulli, "Interaction of bovine mitochondrial ribosomes with messenger RNA," Journal of Biological Chemistry, vol. 264, no. 13, pp. 7518-7522, 1989.

[83] B. S. Laursen, H. P. Sørensen, K. K. Mortensen, and H. U. Sperling-Petersen, "Initiation of protein synthesis in bacteria," Microbiology and Molecular Biology Reviews, vol. 69, no. 1, pp. 101-123, 2005.

[84] M. López-Lastra, A. Rivas, and M. I. Barría, "Protein synthesis in eukaryotes: the growing biological relevance of cap-independent translation initiation," Biological Research, vol. 38, no. 2-3, pp. 121-146, 2005.

[85] B. G. Barrell, S. Anderson, and A. T. Bankier, "Different pattern of codon recognition by mammalian mitochondrial tRNAs," Proceedings of the National Academy of Sciences of the United States of America, vol. 77, no. 6, pp. 3164-3166, 1980.

[86] R. Mikelsaar, "Human mitochondrial genome and the evolution of methionine transfer ribonucleic acids," Journal of Theoretical Biology, vol. 105, no. 2, pp. 221-232, 1983.

[87] A. Marintchev and G. Wagner, "Translation initiation: structures, mechanisms and evolution," Quarterly Reviews of Biophysics, vol. 37, no. 3-4, pp. 197-284, 2004.

[88] A. Roll-Mecak, B.-S. Shin, T. E. Dever, and S. K. Burley, "Engaging the ribosome: universal IFs of translation," Trends in Biochemical Sciences, vol. 26, no. 12, pp. 705-709, 2001.

[89] L. Ma and L. L. Spremulli, "Cloning and sequence analysis of the human mitochondrial translational initiation factor 2 cDNA," Journal of Biological Chemistry, vol. 270, no. 4, pp. 1859-1865, 1995.

[90] E. C. Koc and L. L. Spremulli, "Identification of mammalian mitochondrial translational initiation factor 3 and examination of its role in initiation complex formation with natural mRNAs," Journal of Biological Chemistry, vol. 277, no. 38, pp. 35541-35549, 2002.

[91] L. L. Spremulli, A. Coursey, T. Navratil, and S. E. Hunter, "Initiation and elongation factors in mammalian mitochondrial protein biosynthesis," Progress in Nucleic Acid Research and Molecular Biology, vol. 77, pp. 211-261, 2004.
[92] R. Gaur, D. Grasso, P. P. Datta, et al., "A single mammalian mitochondrial translation initiation factor functionally replaces two bacterial factors," Molecular Cell, vol. 29, no. 2, pp. 180-190, 2008.

[93] M. Hammarsund, W. Wilson, M. Corcoran, et al., "Identification and characterization of two novel human mitochondrial elongation factor genes, hEFG2 and hEFG1, phylogenetically conserved through evolution," Human Genetics, vol. 109, no. 5, pp. 542-550, 2001.

[94] M. Ling, F. Merante, H.-S. Chen, C. Duff, A. M. V. Duncan, and B. H. Robinson, "The human mitochondrial elongation factor tu (EF-Tu) gene: CDNA sequence, genomic localization, genomic structure, and identification of a pseudogene," Gene, vol. 197, no. 1-2, pp. 325-336, 1997.

[95] H. Xin, V. Woriax, W. Burkhart, and L. L. Spremulli, "Cloning and expression of mitochondrial translational elongation factor Ts from bovine and human liver," Journal of Biological Chemistry, vol. 270, no. 29, pp. 17243-17249, 1995.

[96] K. Bhargava, P. Templeton, and L. L. Spremulli, "Expression and characterization of isoform 1 of human mitochondrial elongation factor G," Protein Expression and Purification, vol. 37, no. 2, pp. 368-376, 2004.

[97] E. A. Winzeler, D. D. Shoemaker, A. Astromoff, et al., "Functional characterization of the S. cerevisiae genome by gene deletion and parallel analysis," Science, vol. 285, no. 5429, pp. 901-906, 1999.

[98] M. Tsuboi, H. Morita, Y. Nozaki, et al., "EF-G2mt is an exclusive recycling factor in mammalian mitochondrial protein synthesis," Molecular Cell, vol. 35, no. 4, pp. 502-510, 2009.

[99] G. Bertram, S. Innes, O. Minella, J. P. Richardson, and I. Stansfield, "Endless possibilities: translation termination and stop codon recognition," Microbiology, vol. 147, no. 2, pp. 255-269, 2001.

[100] L. D. Kapp and J. R. Lorsch, "The molecular mechanics of eukaryotic translation," Annual Review of Biochemistry, vol. 73, pp. 657-704, 2004.

[101] Y. Nozaki, N. Matsunaga, T. Ishizawa, T. Ueda, and N. Takeuchi, "HMRF1L is a human mitochondrial translation release factor involved in the decoding of the termination codons UAA and UAG," Genes to Cells, vol. 13, no. 5, pp. 429438, 2008.

[102] H. R. Soleimanpour-Lichaei, I. Kühl, M. Gaisne, et al., "mtRF1a is a human mitochondrial translation release factor decoding the major termination codons UAA and UAG," Molecular Cell, vol. 27, no. 5, pp. 745-757, 2007.

[103] Y. Zhang and L. L. Spremulli, "Identification and cloning of human mitochondrial translational release factor 1 and the ribosome recycling factor," Biochimica et Biophysica Acta, vol. 1443, no. 1-2, pp. 245-250, 1998.

[104] J. Rorbach, R. Richter, H. J. Wessels, et al., "The human mitochondrial ribosome recycling factor is essential for cell viability," Nucleic Acids Research, vol. 36, no. 18, pp. 57875799, 2008.

[105] M. J. Bibb, R. A. Van Etten, C. T. Wright, M. W. Walberg, and D. A. Clayton, "Sequence and gene organization of mouse mitochondrial DNA," Cell, vol. 26, no. 2, pp. 167-180, 1981.

[106] G. Gadaleta, G. Pepe, G. De Candia, C. Quagliariello, E. Sbisa, and C. Saccone, "The complete nucleotide sequence of the Rattus norvegicus mitochondrial genome: cryptic signals revealed by comparative analysis between vertebrates," Journal of Molecular Evolution, vol. 28, no. 6, pp. 497-516, 1989.

[107] P. Smits, J. A. M. Smeitink, L. P. van den Heuvel, M. A. Huynen, and T. J. G. Ettema, "Reconstructing the evolution 
of the mitochondrial ribosomal proteome," Nucleic Acids Research, vol. 35, no. 14, pp. 4686-4703, 2007.

[108] T. W. O'Brien, "Properties of human mitochondrial ribosomes," IUBMB Life, vol. 55, no. 9, pp. 505-513, 2003.

[109] M. R. Sharma, E. C. Koc, P. P. Datta, T. M. Booth, L. L. Spremulli, and R. K. Agrawal, "Structure of the mammalian mitochondrial ribosome reveals an expanded functional role for its component proteins," Cell, vol. 115, no. 1, pp. 97-108, 2003.

[110] M. Helm, H. Brulé, D. Friede, R. Giegé, D. Pütz, and C. Florentz, "Search for characteristic structural features of mammalian mitochondrial tRNAs," RNA, vol. 6, no. 10, pp. 1356-1379, 2000.

[111] M. Helm, "Post-transcriptional nucleotide modification and alternative folding of RNA," Nucleic Acids Research, vol. 34, no. 2, pp. 721-733, 2006.

[112] M. Helm, R. Giegé, and C. Florentz, "A Watson-Crick base-pair-disrupting methyl group (m1A9) is sufficient for cloverleaf folding of human mitochondrial tRNA(Lys)," Biochemistry, vol. 38, no. 40, pp. 13338-13346, 1999.

[113] Y. Kirino and T. Suzuki, "Human mitochondrial diseases associated with tRNA wobble modification deficiency," RNA Biology, vol. 2, no. 2, pp. 41-44, 2005.

[114] R. Giegé, M. Sissler, and C. Florentz, "Universal rules and idiosyncratic features in tRNA identity," Nucleic Acids Research, vol. 26, no. 22, pp. 5017-5035, 1998.

[115] L. Bonnefond, A. Fender, J. Rudinger-Thirion, R. Giegé, C. Florentz, and M. Sissler, "Toward the full set of human mitochondrial aminoacyl-tRNA synthetases: characterization of AspRS and TyrRS," Biochemistry, vol. 44, no. 12, pp. 48054816, 2005.

[116] S. M. K. Davies, O. Rackham, A.-M. J. Shearwood, et al., "Pentatricopeptide repeat domain protein 3 associates with the mitochondrial small ribosomal subunit and regulates translation," FEBS Letters, vol. 583, no. 12, pp. 1853-1858, 2009.

[117] V. Ramakrishnan, "Ribosome structure and the mechanism of translation," Cell, vol. 108, no. 4, pp. 557-572, 2002.

[118] C. N. Jones, K. A. Wilkinson, K. T. Hung, K. M. Weeks, and L. L. Spremulli, "Lack of secondary structure characterizes the $5^{\prime}$ ends of mammalian mitochondrial mRNAs," RNA, vol. 14, no. 5, pp. 862-871, 2008.

[119] B. E. Christian and L. L. Spremulli, "Evidence for an active role of IF3mt in the initiation of translation in mammalian mitochondria," Biochemistry, vol. 48, no. 15, pp. 3269-3278, 2009.

[120] K. Bhargava and L. L. Spremulli, "Role of the N- and Cterminal extensions on the activity of mammalian mitochondrial translational initiation factor 3," Nucleic Acids Research, vol. 33, no. 22, pp. 7011-7018, 2005.

[121] H.-X. Liao and L. L. Spremulli, "Identification and initial characterization of translational initiation factor 2 from bovine mitochondria," Journal of Biological Chemistry, vol. 265, no. 23, pp. 13618-13622, 1990.

[122] J. Ma and L. L. Spremulli, "Expression, purification, and mechanistic studies of bovine mitochondrial translational initiation factor 2," Journal of Biological Chemistry, vol. 271, no. 10, pp. 5805-5811, 1996.

[123] Md. E. Haque, D. Grasso, and L. L. Spremulli, "The interaction of mammalian mitochondrial translational initiation factor 3 with ribosomes: evolution of terminal extensions in IF3mt," Nucleic Acids Research, vol. 36, no. 2, pp. 589-597, 2008.
[124] Y.-C. Cai, J. M. Bullard, N. L. Thompson, and L. L. Spremulli, "Interaction of mitochondrial elongation factor Tu with aminoacyl-tRNA and elongation factor Ts," Journal of Biological Chemistry, vol. 275, no. 27, pp. 20308-20314, 2000.

[125] V. L. Woriax, J. M. Bullard, L. Ma, T. Yokogawa, and L. L. Spremulli, "Mechanistic studies of the translational elongation cycle in mammalian mitochondria," Biochimica et Biophysica Acta, vol. 1352, no. 1, pp. 91-101, 1997.

[126] F. Sasarman, H. Antonicka, and E. A. Shoubridge, "The A3243G tRNALeu(UUR) MELAS mutation causes amino acid misincorporation and a combined respiratory chain assembly defect partially suppressed by overexpression of EFTu and EFG2," Human Molecular Genetics, vol. 17, no. 23, pp. 3697-3707, 2008.

[127] A. Nagao, T. Suzuki, and T. Suzuki, "Aminoacyl-tRNA surveillance by EF-Tu in mammalian mitochondria," Nucleic Acids Symposium Series, no. 51, pp. 41-42, 2007.

[128] J. A. Mears, J. J. Cannone, S. M. Stagg, R. R. Gutell, R. K. Agrawal, and S. C. Harvey, "Modeling a minimal ribosome based on comparative sequence analysis," Journal of Molecular Biology, vol. 321, no. 2, pp. 215-234, 2002.

[129] J. A. Mears, M. R. Sharma, R. R. Gutell, et al., "A structural model for the large subunit of the mammalian mitochondrial ribosome," Journal of Molecular Biology, vol. 358, no. 1, pp. 193-212, 2006

[130] J. Towpik, "Regulation of mitochondrial translation in yeast," Cellular and Molecular Biology Letters, vol. 10, no. 4, pp. 571594, 2005.

[131] A. Chacinska and M. Boguta, "Coupling of mitochondrial translation with the formation of respiratory complexes in yeast mitochondria," Acta Biochimica Polonica, vol. 47, no. 4, pp. 973-991, 2000.

[132] X. Zeng, A. Hourset, and A. Tzagoloff, "The Saccharomyces cerevisiae ATP22 gene codes for the mitochondrial ATPase subunit 6-specific translation factor," Genetics, vol. 175, no. 1, pp. 55-63, 2007.

[133] E. C. Koc and L. L. Spremulli, "RNA-binding proteins of mammalian mitochondria," Mitochondrion, vol. 2, no. 4, pp. 277-291, 2003.

[134] W. Weraarpachai, H. Antonicka, F. Sasarman, et al., "Mutation in TACO1, encoding a translational activator of COX I, results in cytochrome c oxidase deficiency and late-onset Leigh syndrome," Nature Genetics, vol. 41, no. 7, pp. 833-837, 2009.

[135] M. S. Rodeheffer, B. E. Boone, A. C. Bryan, and G. S. Shadel, "Namlp, a protein involved in RNA processing and translation, is coupled to transcription through an interaction with yeast mitochondrial RNA polymerase," Journal of Biological Chemistry, vol. 276, no. 11, pp. 8616-8622, 2001.

[136] V. K. Mootha, P. Lepage, K. Miller, et al., "Identification of a gene causing human cytochrome $c$ oxidase deficiency by integrative genomics," Proceedings of the National Academy of Sciences of the United States of America, vol. 100, no. 2, pp. 605-610, 2003.

[137] G. M. Manthey and J. E. McEwen, "The product of the nuclear gene PET309 is required for translation of mature mRNA and stability or production of intron-containing RNAs derived from the mitochondrial COX1 locus of Saccharomyces cerevisiae," EMBO Journal, vol. 14, no. 16, pp. 4031-4043, 1995.

[138] F. Xu, C. Morin, G. Mitchell, C. Ackerley, and B. H. Robinson, "The role of the LRPPRC (leucine-rich pentatricopeptide 
repeal cassette) gene in cytochrome oxidase assembly: mutation causes lowered levels of COX (cytochrome c oxidase) I and COX III mRNA," Biochemical Journal, vol. 382, no. 1, pp. 331-336, 2004.

[139] S. Naithani, S. A. Saracco, C. A. Butler, and T. D. Fox, "Interactions among COX1, COX2, and COX3 mRNAspecific translational activator proteins on the inner surface of the mitochondrial inner membrane of Saccharomyces cerevisiae," Molecular Biology of the Cell, vol. 14, no. 1, pp. 324-333, 2003.

[140] M. G. Wallis, O. Groudinsky, P. P. Slonimski, and G. Dujardin, "The NAM1 protein (NAM1p), which is selectively required for cox1, cytb and atp6 transcript processing/stabilisation, is located in the yeast mitochondrial matrix," European Journal of Biochemistry, vol. 222, no. 1, pp. 27-32, 1994.

[141] G. S. Shadel, "Coupling the mitochondrial transcription machinery to human disease," Trends in Genetics, vol. 20, no. 10, pp. 513-519, 2004.

[142] S. Mili and S. Piñol-Roma, "LRP130, a pentatricopeptide motif protein with a noncanonical RNA-binding domain, is bound in vivo to mitochondrial and nuclear RNAs," Molecular and Cellular Biology, vol. 23, no. 14, pp. 4972-4982, 2003.

[143] M. Nolden, S. Ehses, M. Koppen, A. Bernacchia, E. I. Rugarli, and T. Langer, "The m-AAA protease defective in hereditary spastic paraplegia controls ribosome assembly in mitochondria," Cell, vol. 123, no. 2, pp. 277-289, 2005.

[144] G. Casari, M. De Fusco, S. Ciarmatori, et al., "Spastic paraplegia and OXPHOS impairment caused by mutations in paraplegin, a nuclear-encoded mitochondrial metalloprotease," Cell, vol. 93, no. 6, pp. 973-983, 1998.

[145] G. S. Shadel, "Expression and maintenance of mitochondrial DNA: new insights into human disease pathology," American Journal of Pathology, vol. 172, no. 6, pp. 1445-1456, 2008.

[146] J. Cotney, Z. Wang, and G. S. Shadel, "Relative abundance of the human mitochondrial transcription system and distinct roles for h-mtTFB1 and h-mtTFB2 in mitochondrial biogenesis and gene expression," Nucleic Acids Research, vol. 35, no. 12, pp. 4042-4054, 2007

[147] Y. Bykhovskaya, E. Mengesha, D. Wang, et al., "Human mitochondrial transcription factor $\mathrm{B} 1$ as a modifier gene for hearing loss associated with the mitochondrial A1555G mutation," Molecular Genetics and Metabolism, vol. 82, no. 1, pp. 27-32, 2004.

[148] M. D. Metodiev, N. Lesko, C. B. Park, et al., "Methylation of $12 \mathrm{~S}$ rRNA is necessary for in vivo stability of the small subunit of the mammalian mitochondrial ribosome," Cell Metabolism, vol. 9, no. 4, pp. 386-397, 2009.

[149] R. C. Scarpulla, "Transcriptional paradigms in mammalian mitochondrial biogenesis and function," Physiological Reviews, vol. 88, no. 2, pp. 611-638, 2008.

[150] D. De Rasmo, A. Signorile, E. Roca, and S. Papa, "CAMP response element-binding protein (CREB) is imported into mitochondria and promotes protein synthesis," FEBS Journal, vol. 276, no. 16, pp. 4325-4333, 2009.

[151] S.-L. Liang, D. Quirk, and A. Zhou, "RNase L: its biological roles and regulation," IUBMB Life, vol. 58, no. 9, pp. 508-514, 2006.

[152] F. Le Roy, M. Silhol, T. Salehzada, and C. Bisbal, "Regulation of mitochondrial mRNA stability by RNase L is translationdependent and controls IFN $\alpha$-induced apoptosis," Cell Death and Differentiation, vol. 14, no. 8, pp. 1406-1413, 2007.
[153] H. Suzuki, T. Ueda, H. Taguchi, and N. Takeuchi, "Chaperone properties of mammalian mitochondrial translation elongation factor Tu," Journal of Biological Chemistry, vol. 282, no. 6, pp. 4076-4084, 2007.

[154] A. Malki, T. Caldas, J. Abdallah, et al., "Peptidase activity of the Escherichia coli Hsp31 chaperone," Journal of Biological Chemistry, vol. 280, no. 15, pp. 14420-14426, 2005.

[155] Z. Wang, J. Cotney, and G. S. Shadel, "Human mitochondrial ribosomal protein MRPL12 interacts directly with mitochondrial RNA polymerase to modulate mitochondrial gene expression," Journal of Biological Chemistry, vol. 282, no. 17, pp. 12610-12618, 2007.

[156] E. C. Koc, A. Ranasinghe, W. Burkhart, et al., "A new face on apoptosis: death-associated protein 3 and PDCD9 are mitochondrial ribosomal proteins," FEBS Letters, vol. 492, no. 1-2, pp. 166-170, 2001.

[157] W. Voos and K. Röttgers, "Molecular chaperones as essential mediators of mitochondrial biogenesis," Biochimica et Biophysica Acta, vol. 1592, no. 1, pp. 51-62, 2002.

[158] M. Koppen and T. Langer, "Protein degradation within mitochondria: versatile activities of AAA proteases and other peptidases," Critical Reviews in Biochemistry and Molecular Biology, vol. 42, no. 3, pp. 221-242, 2007.

[159] L. G. J. Nijtmans, S. M. Artal, L. A. Grivell, and P. J. Coates, "The mitochondrial PHB complex: roles in mitochondrial respiratory complex assembly, ageing and degenerative disease," Cellular and Molecular Life Sciences, vol. 59, no. 1, pp. 143-155, 2002.

[160] M. Artal-Sanz and N. Tavernarakis, "Prohibitin and mitochondrial biology," Trends in Endocrinology and Metabolism, vol. 20, no. 8, pp. 394-401, 2009.

[161] M. Liu and L. Spremulli, "Interaction of mammalian mitochondrial ribosomes with the inner membrane," Journal of Biological Chemistry, vol. 275, no. 38, pp. 29400-29406, 2000.

[162] K. Hell, J. M. Herrmann, E. Pratje, W. Neupert, and R. A. Stuart, "Oxalp, an essential component of the N-tail protein export machinery in mitochondria," Proceedings of the National Academy of Sciences of the United States of America, vol. 95, no. 5, pp. 2250-2255, 1998.

[163] K. Hell, W. Neupert, and R. A. Stuart, "Oxalp acts as a general membrane insertion machinery for proteins encoded by mitochondrial DNA," EMBO Journal, vol. 20, no. 6, pp. 1281-1288, 2001.

[164] M. Ott, M. Prestele, H. Bauerschmitt, S. Funes, N. Bonnefoy, and J. M. Herrmann, "Mbal, a membrane-associated ribosome receptor in mitochondria," EMBO Journal, vol. 25, no. 8, pp. 1603-1610, 2006.

[165] M. E. Sanchirico, T. D. Fox, and T. L. Mason, "Accumulation of mitochondrially synthesized Saccharomyces cerevisiae Cox $2 p$ and Cox $3 p$ depends on targeting information in untranslated portions of their mRNAs," EMBO Journal, vol. 17, no. 19, pp. 5796-5804, 1998.

[166] K. Watson, "The organization of ribosomal granules within mitochondrial structures of aerobic and anaerobic cells of Saccharomyces cerevisae," Journal of Cell Biology, vol. 55, no. 3, pp. 721-726, 1972.

[167] R. A. Stuart, "Insertion of proteins into the inner membrane of mitochondria: the role of the Oxa1 complex," Biochimica et Biophysica Acta, vol. 1592, no. 1, pp. 79-87, 2002.

[168] N. Bonnefoy, H. L. Fiumera, G. Dujardin, and T. D. Fox, "Roles of Oxal-related inner-membrane translocases in assembly of respiratory chain complexes," Biochimica et Biophysica Acta, vol. 1793, no. 1, pp. 60-70, 2009. 
[169] L. Jia, M. Dienhart, M. Schramp, M. McCauley, K. Hell, and R. A. Stuart, "Yeast Oxal interacts with mitochondrial ribosomes: the importance of the C-terminal region of Oxa1,” EMBO Journal, vol. 22, no. 24, pp. 6438-6447, 2003.

[170] L. Jia, J. Kaur, and R. A. Stuart, "Mapping of the saccharomyces cerevisiae oxa1-mitochondrial ribosome interface and identification of MrpL40, a ribosomal protein in close proximity to oxal and critical for oxidative phosphorylation complex assembly," Eukaryotic Cell, vol. 8, no. 11, pp. 17921802, 2009.

[171] M. Preuss, K. Leonhard, K. Hell, R. A. Stuart, W. Neupert, and J. M. Herrmann, "Mba1, a novel component of the mitochondrial protein export machinery of the yeast Saccharomyces cerevisiae," Journal of Cell Biology, vol. 153, no. 5, pp. 1085-1096, 2001.

[172] S. Schlickum, A. Moghekar, J. C. Simpson, et al., "LETM1, a gene deleted in Wolf-Hirschhorn syndrome, encodes an evolutionarily conserved mitochondrial protein," Genomics, vol. 83, no. 2, pp. 254-261, 2004.

[173] A. E. Frazier, R. D. Taylor, D. U. Mick, et al., "Mdm38 interacts with ribosomes and is a component of the mitochondrial protein export machinery," Journal of Cell Biology, vol. 172, no. 4, pp. 553-564, 2006.

[174] L. Piao, Y. Li, S. J. Kim, et al., "Association of LETM1 and mrpl36 contributes to the regulation of mitochondrial ATP production and necrotic cell death," Cancer Research, vol. 69, no. 8, pp. 3397-3404, 2009.

[175] S. Tamai, H. Iida, S. Yokota, et al., "Characterization of the mitochondrial protein LETM1, which maintains the mitochondrial tubular shapes and interacts with the AAAATPase BCS1L," Journal of Cell Science, vol. 121, no. 15, pp. 2588-2600, 2008.

[176] K. S. Dimmer, F. Navoni, A. Casarin, et al., "LETM1, deleted in Wolf-Hirschhorn syndrome is required for normal mitochondrial morphology and cellular viability," Human Molecular Genetics, vol. 17, no. 2, pp. 201-214, 2008.

[177] A. S. Lynch and J. C. Wang, "Anchoring of DNA to the bacterial cytoplasmic membrane through cotranscriptional synthesis of polypeptides encoding membrane proteins or proteins for export: a mechanism of plasmid hypernegative supercoiling in mutants deficient in DNA topoisomerase I," Journal of Bacteriology, vol. 175, no. 6, pp. 1645-1655, 1993.

[178] G. H. Vos-Scheperkeuter and B. Witholt, "Co-translational insertion of envelope proteins: theoretical considerations and implications," Annales de Microbiologie, vol. 133A, no. 1, pp. 129-138, 1982.

[179] M. Trinei, J.-P. Vannier, M. Beurton-Aimar, and V. Norris, "A hyperstructure approach to mitochondria," Molecular Microbiology, vol. 53, no. 1, pp. 41-53, 2004.

[180] E. Fernández-Vizarra, V. Tiranti, and M. Zeviani, “Assembly of the oxidative phosphorylation system in humans: what we have learned by studying its defects," Biochimica et Biophysica Acta, vol. 1793, no. 1, pp. 200-211, 2009.

[181] I. Ogilvie, N. G. Kennaway, and E. A. Shoubridge, "A molecular chaperone for mitochondrial complex I assembly is mutated in a progressive encephalopathy," Journal of Clinical Investigation, vol. 115, no. 10, pp. 2784-2792, 2005.

[182] R. O. Vogel, R. J. R. J. Janssen, C. Ugalde, et al., "Human mitochondrial complex I assembly is mediated by NDUFAF1," FEBS Journal, vol. 272, no. 20, pp. 5317-5326, 2005.

[183] S. J. G. Hoefs, C. E. J. Dieteren, R. J. Rodenburg, et al., "Baculovirus complementation restores a novel NDUFAF2 mutation causing complex I deficiency," Human Mutation, vol. 30, no. 7, pp. E728-E736, 2009.
[184] A. Saada, R. O. Vogel, S. J. Hoefs, et al., "Mutations in NDUFAF3 (C3ORF60), encoding an NDUFAF4 (C6ORF66)interacting complex I assembly protein, cause fatal neonatal mitochondrial disease," American Journal of Human Genetics, vol. 84, no. 6, pp. 718-727, 2009.

[185] A. Saada, S. Edvardson, M. Rapoport, et al., "C6ORF66 is an assembly factor of mitochondrial complex I," American Journal of Human Genetics, vol. 82, no. 1, pp. 32-38, 2008.

[186] R. O. Vogel, R. J. R. J. Janssen, M. A. M. van den Brand, et al., "Cytosolic signaling protein Ecsit also localizes to mitochondria where it interacts with chaperone NDUFAF1 and functions in complex I assembly," Genes and Development, vol. 21, no. 5, pp. 615-624, 2007.

[187] D. J. Pagliarini, S. E. Calvo, B. Chang, et al., "A mitochondrial protein compendium elucidates complex I disease biology," Cell, vol. 134, no. 1, pp. 112-123, 2008.

[188] M. Gerards, W. Sluiter, B. J. van den Bosch, et al., "Defective complex I assembly due to C20orf7 mutations as a new cause of Leigh syndrome," Journal of Medical Genetics. In press.

[189] C. Sugiana, D. J. Pagliarini, M. McKenzie, et al., "Mutation of C20orf7 disrupts complex I assembly and causes lethal neonatal mitochondrial disease," American Journal of Human Genetics, vol. 83, no. 4, pp. 468-478, 2008.

[190] R. O. Vogel, J. A. M. Smeitink, and L. G. J. Nijtmans, "Human mitochondrial complex I assembly: a dynamic and versatile process," Biochimica et Biophysica Acta, vol. 1767, no. 10, pp. 1215-1227, 2007.

[191] N. Vahsen, C. Candé, J.-J. Brière, et al., "AIF deficiency compromises oxidative phosphorylation," EMBO Journal, vol. 23, no. 23, pp. 4679-4689, 2004.

[192] K. Bych, S. Kerscher, D. J. A. Netz, et al., "The iron-sulphur protein Ind1 is required for effective complex I assembly," EMBO Journal, vol. 27, no. 12, pp. 1736-1746, 2008.

[193] D. Ghezzi, P. Goffrini, G. Uziel, et al., "SDHAF1, encoding a LYR complex-II specific assembly factor, is mutated in SDHdefective infantile leukoencephalopathy," Nature Genetics, vol. 41, no. 6, pp. 654-656, 2009.

[194] P. de Lonlay, I. Valnot, A. Barrientos, et al., "A mutant mitochondrial respiratory chain assembly protein causes complex III deficiency in patients with tubulopathy, encephalopathy and liver failure," Nature Genetics, vol. 29, no. 1, pp. 57-60, 2001.

[195] P. Pecinai, H. Houškková, H. Hansíková, J. Zeman, and J. Houštěk, "Genetic defects of cytochrome c oxidase assembly," Physiological Research, vol. 53, supplement 1, pp. S213-S223, 2004.

[196] Z.-G. Wang, P. S. White, and S. H. Ackerman, "Atp11p and Atp12p are assembly factors for the F1-ATPase in human mitochondria," Journal of Biological Chemistry, vol. 276, no. 33, pp. 30773-30778, 2001.

[197] X. Zeng, W. Neupert, and A. Tzagoloff, "The metalloprotease encoded by ATP23 has a dual function in processing and assembly of subunit 6 of mitochondrial ATPase," Molecular Biology of the Cell, vol. 18, no. 2, pp. 617-626, 2007.

[198] L. Stiburek, D. Fornuskova, L. Wenchich, M. Pejznochova, H. Hansikova, and J. Zeman, "Knockdown of human Oxall impairs the biogenesis of F1Fo-ATP synthase and NADH:ubiquinone oxidoreductase," Journal of Molecular Biology, vol. 374, no. 2, pp. 506-516, 2007.

[199] N. V. Dudkina, S. Sunderhaus, E. J. Boekema, and H.-P. Braun, "The higher level of organization of the oxidative phosphorylation system: mitochondrial supercomplexes," Journal of Bioenergetics and Biomembranes, vol. 40, no. 5, pp. 419-424, 2008. 
[200] E. A. Schon and N. A. Dencher, "Heavy breathing: energy conversion by mitochondrial respiratory supercomplexes," Cell Metabolism, vol. 9, no. 1, pp. 1-3, 2009.

[201] R. Acín-Pérez, P. Fernández-Silva, M. L. Peleato, A. PérezMartos, and J. A. Enriquez, "Respiratory active mitochondrial supercomplexes," Molecular Cell, vol. 32, no. 4, pp. 529539, 2008.

[202] H. Schägger, R. De Coo, M. F. Bauer, S. Hofmann, C. Godino, and U. Brandt, "Significance of respirasomes for the assembly/stability of human respiratory chain complex I," Journal of Biological Chemistry, vol. 279, no. 35, pp. 3634936353, 2004.

[203] M. McKenzie, M. Lazarou, D. R. Thorburn, and M. T. Ryan, "Mitochondrial respiratory chain supercomplexes are destabilized in Barth Syndrome patients," Journal of Molecular Biology, vol. 361, no. 3, pp. 462-469, 2006.

[204] H. Chen and D. C. Chan, "Emerging functions of mammalian mitochondrial fusion and fission," Human Molecular Genetics, vol. 14, no. 2, pp. R283-R289, 2005.

[205] M. Liesa, M. Palacin, and A. Zorzano, "Mitochondrial dynamics in mammalian health and disease," Physiological Reviews, vol. 89, no. 3, pp. 799-845, 2009.

[206] P. A. Parone, S. Da Cruz, D. Tondera, et al., "Preventing mitochondrial fission impairs mitochondrial function and leads to loss of mitochondrial DNA," PLoS One, vol. 3, no. 9, article e3257, 2008.

[207] H. R. Waterham, J. Koster, C. W. T. van Roermund, P. A. W. Mooyer, R. J. A. Wanders, and J. V. Leonard, "A lethal defect of mitochondrial and peroxisomal fission," New England Journal of Medicine, vol. 356, no. 17, pp. 1736-1741, 2007.

[208] I. J. Holt, A. E. Harding, and J. A. Morgan-Hughes, "Deletions of muscle mitochondrial DNA in patients with mitochondrial myopathies," Nature, vol. 331, no. 6158, pp. 717-719, 1988.

[209] D. C. Wallace, G. Singh, M. T. Lott, et al., "Mitochondrial DNA mutation associated with Leber's hereditary optic neuropathy," Science, vol. 242, no. 4884, pp. 1427-1430, 1988.

[210] F. Scaglia and L.-J. C. Wong, "Human mitochondrial transfer RNAs: role of pathogenic mutation in disease," Muscle and Nerve, vol. 37, no. 2, pp. 150-171, 2008.

[211] C. Florentz, B. Sohm, P. Tryoen-Tóth, J. Pütz, and M. Sissler, "Human mitochondrial tRNAs in health and disease," Cellular and Molecular Life Sciences, vol. 60, no. 7, pp. 13561375, 2003.

[212] E. Zifa, S. Giannouli, P. Theotokis, C. Stamatis, Z. Mamuris, and C. Stathopoulos, "Mitochondrial tRNA mutations: clinical and functional perturbations," RNA Biology, vol. 4, no. 1, pp. 38-66, 2007.

[213] S. S. L. Chan and W. C. Copeland, "DNA polymerase gamma and mitochondrial disease: understanding the consequence of POLG mutations," Biochimica et Biophysica Acta, vol. 1787, no. 5, pp. 312-319, 2009.

[214] M. J. Longley, S. Clark, C. Y. W. Man, et al., "Mutant POLG2 disrupts DNA polymerase $\gamma$ subunits and causes progressive external ophthalmoplegia," American Journal of Human Genetics, vol. 78, no. 6, pp. 1026-1034, 2006.

[215] J. A. Mayr, O. Merkel, S. D. Kohlwein, et al., "Mitochondrial phosphate-carrier deficiency: a novel disorder of oxidative phosphorylation," American Journal of Human Genetics, vol. 80, no. 3, pp. 478-484, 2007.

[216] E. Ostergaard, E. Christensen, E. Kristensen, et al., "Deficiency of the $\alpha$ subunit of succinate-coenzyme A ligase causes fatal infantile lactic acidosis with mitochondrial DNA depletion," American Journal of Human Genetics, vol. 81, no. 2, pp. 383-387, 2007.

[217] A. Bourdon, L. Minai, V. Serre, et al., "Mutation of RRM2B, encoding p53-controlled ribonucleotide reductase (p53R2), causes severe mitochondrial DNA depletion," Nature Genetics, vol. 39, no. 6, pp. 776-780, 2007.

[218] K. D. Hauff and G. M. Hatch, "Cardiolipin metabolism and Barth Syndrome," Progress in Lipid Research, vol. 45, no. 2, pp. 91-101, 2006.

[219] E. I. Rugarli and T. Langer, "Translating m-AAA protease function in mitochondria to hereditary spastic paraplegia," Trends in Molecular Medicine, vol. 12, no. 6, pp. 262-269, 2006.

[220] G. M. C. Janssen, J. A. Maassen, and J. M. W. van Den Ouweland, "The diabetes-associated 3243 mutation in the mitochondrial tRNA(Leu(UUR)) gene causes severe mitochondrial dysfunction without a strong decrease in protein synthesis rate," Journal of Biological Chemistry, vol. 274, no. 42, pp. 29744-29748, 1999.

[221] M. Toompuu, V. Tiranti, M. Zeviani, and H. T. Jacobs, "Molecular phenotype of the np 7472 deafness-associated mitochondrial mutation in osteosarcoma cell cybrids," Human Molecular Genetics, vol. 8, no. 12, pp. 2275-2283, 1999.

[222] H. T. Jacobs, "Disorders of mitochondrial protein synthesis," Human Molecular Genetics, vol. 12, no. 2, pp. R293-R301, 2003.

[223] J. Finsterer, "Genetic, pathogenetic, and phenotypic implications of the mitochondrial A3243G tRNALeu(UUR) mutation," Acta Neurologica Scandinavica, vol. 116, no. 1, pp. 1-14, 2007.

[224] H. T. Jacobs and I. J. Holt, "The np 3243 MELAS mutation: damned if you aminoacylate, damned if you don't," Human Molecular Genetics, vol. 9, no. 4, pp. 463-465, 2000.

[225] Y. Kirino, T. Yasukawa, S. Ohta, et al., "Codon-specific translational defect caused by a wobble modification deficiency in mutant tRNA from a human mitochondrial disease," Proceedings of the National Academy of Sciences of the United States of America, vol. 101, no. 42, pp. 15070-15075, 2004.

[226] M. P. King, Y. Koga, M. Davidson, and E. A. Schon, "Defects in mitochondrial protein synthesis and respiratory chain activity segregate with the tRNA(Leu(UUR)) mutation associated with mitochondrial myopathy, encephalopathy, lactic acidosis, and strokelike episodes," Molecular and Cellular Biology, vol. 12, no. 2, pp. 480-490, 1992.

[227] J. A. Enriquez, A. Chomyn, and G. Attardi, "MtDNA mutation in MERRF syndrome causes defective aminoacylation of tRNA(Lys) and premature translation termination," Nature Genetics, vol. 10, no. 1, pp. 47-55, 1995.

[228] G. Xing, Z. Chen, and X. Cao, "Mitochondrial rRNA and tRNA and hearing function," Cell Research, vol. 17, no. 3, pp. 227-239, 2007.

[229] E. Cardaioli, M. T. Dotti, G. Hayek, M. Zappella, and A. Federico, "Studies on mitochondrial pathogenesis of Rett syndrome: ultrastructural data from skin and muscle biopsies and mutational analysis at mtDNA nucleotides 10463 and 2835," Journal of Submicroscopic Cytology and Pathology, vol. 31, no. 2, pp. 301-304, 1999.

[230] R.-H. Hsieh, J.-Y. Li, C.-Y. Pang, and Y.-H. Wei, "A novel mutation in the mitochondrial 16S rRNA gene in a patient with MELAS syndrome, diabetes mellitus, hyperthyroidism and cardiomyopathy," Journal of Biomedical Science, vol. 8, no. 4, pp. 328-335, 2001. 
[231] J. M. Shoffner, M. D. Brown, A. Torroni, et al., "Mitochondrial DNA variants observed in Alzheimer disease and Parkinson disease patients," Genomics, vol. 17, no. 1, pp. 171184, 1993.

[232] J. Rozenski, P. F. Crain, and J. A. McCloskey, "The RNA modification database: 1999 update," Nucleic Acids Research, vol. 27, no. 1, pp. 196-197, 1999.

[233] Y. Bykhovskaya, E. Mengesha, and N. Fischel-Ghodsian, "Pleiotropic effects and compensation mechanisms determine tissue specificity in mitochondrial myopathy and sideroblastic anemia (MLASA)," Molecular Genetics and Metabolism, vol. 91, no. 2, pp. 148-156, 2007.

[234] S. S. Ashraf, E. Sochacka, R. Cain, R. Guenther, A. Malkiewicz, and P. F. Agris, "Single atom modification $(\mathrm{O} \rightarrow$ S) of tRNA confers ribosome binding," RNA, vol. 5, no. 2, pp. 188-194, 1999.

[235] C. Yarian, M. Marszalek, E. Sochacka, et al., "Modified nucleoside dependent Watson-Crick and wobble codon binding by tRNA(Lys)(UUU) species," Biochemistry, vol. 39, no. 44, pp. 13390-13395, 2000.

[236] L. Valente, N. Shigi, T. Suzuki, and M. Zeviani, "The R336Q mutation in human mitochondrial EFTu prevents the formation of an active mt-EFTu - GTP · aa-tRNA ternary complex," Biochimica et Biophysica Acta, vol. 1792, no. 8, pp. 791-795, 2009.

[237] K. A. Dittmar, J. M. Goodenbour, and T. Pan, "Tissuespecific differences in human transfer RNA expression," PLoS Genetics, vol. 2, no. 12, article e221, 2006.

[238] A. Tzagoloff and A. Shtanko, "Mitochondrial and cytoplasmic isoleucyl-, glutamyl- and arginyl-tRNA synthetases of yeast are encoded by separate genes," European Journal of Biochemistry, vol. 230, no. 2, pp. 582-586, 1995.

[239] A. Arnoldi, A. Tonelli, F. Crippa, et al., "A clinical, genetic, and biochemical characterization of SPG7 mutations in a large cohort of patients with hereditary spastic paraplegia," Human Mutation, vol. 29, no. 4, pp. 522-531, 2008.

[240] L. Atorino, L. Silvestri, M. Koppen, et al., "Loss of m-AAA protease in mitochondria causes complex I deficiency and increased sensitivity to oxidative stress in hereditary spastic paraplegia," Journal of Cell Biology, vol. 163, no. 4, pp. 777787, 2003.

[241] P. A. Wilkinson, A. H. Crosby, C. Turner, et al., "A clinical, genetic and biochemical study of SPG7 mutations in hereditary spastic paraplegia," Brain, vol. 127, no. 5, pp. 973-980, 2004.

[242] M. Koppen, M. D. Metodiev, G. Casari, E. I. Rugarli, and T. Langer, "Variable and tissue-specific subunit composition of mitochondrial m-AAA protease complexes linked to hereditary spastic paraplegia," Molecular and Cellular Biology, vol. 27, no. 2, pp. 758-767, 2007.

[243] V. Tiranti, P. D’Adamo, E. Briem, et al., "Ethylmalonic encephalopathy is caused by mutations in ETHE1, a gene encoding a mitochondrial matrix protein," American Journal of Human Genetics, vol. 74, no. 2, pp. 239-252, 2004.

[244] W. J. Ansorge, "Next-generation DNA sequencing techniques," New Biotechnology, vol. 25, no. 4, pp. 195-203, 2009.

[245] T. Tucker, M. Marra, and J. M. Friedman, "Massively parallel sequencing: the next big thing in genetic medicine," American Journal of Human Genetics, vol. 85, no. 2, pp. 142-154, 2009.

[246] S. B. Ng, E. H. Turner, P. D. Robertson, et al., "Targeted capture and massively parallel sequencing of 12 human exomes," Nature, vol. 461, no. 7261, pp. 272-276, 2009.
[247] G. J. Porreca, K. Zhang, J. B. Li, et al., "Multiplex amplification of large sets of human exons," Nature Methods, vol. 4, no. 11, pp. 931-936, 2007.

[248] B. Lehner, C. Crombie, J. Tischler, A. Fortunato, and A. G. Fraser, "Systematic mapping of genetic interactions in Caenorhabditis elegans identifies common modifiers of diverse signaling pathways," Nature Genetics, vol. 38, no. 8, pp. 896-903, 2006.

[249] S. DiMauro and M. Mancuso, "Mitochondrial diseases: therapeutic approaches," Bioscience Reports, vol. 27, no. 1-3, pp. 125-137, 2007.

[250] S. Koene and J. Smeitink, "Mitochondrial medicine: entering the era of treatment," Journal of Internal Medicine, vol. 265, no. 2, pp. 193-209, 2009. 

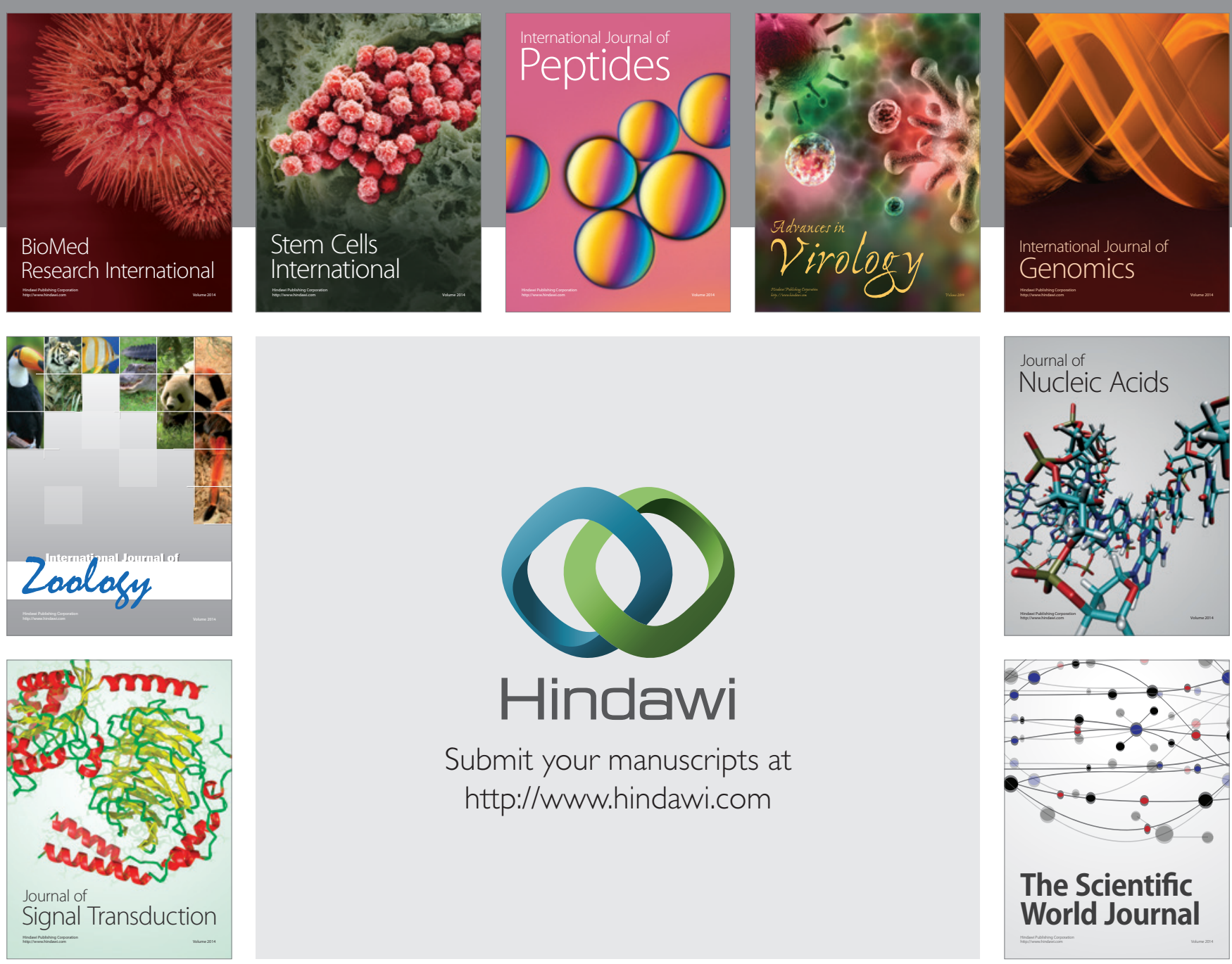

Submit your manuscripts at

http://www.hindawi.com
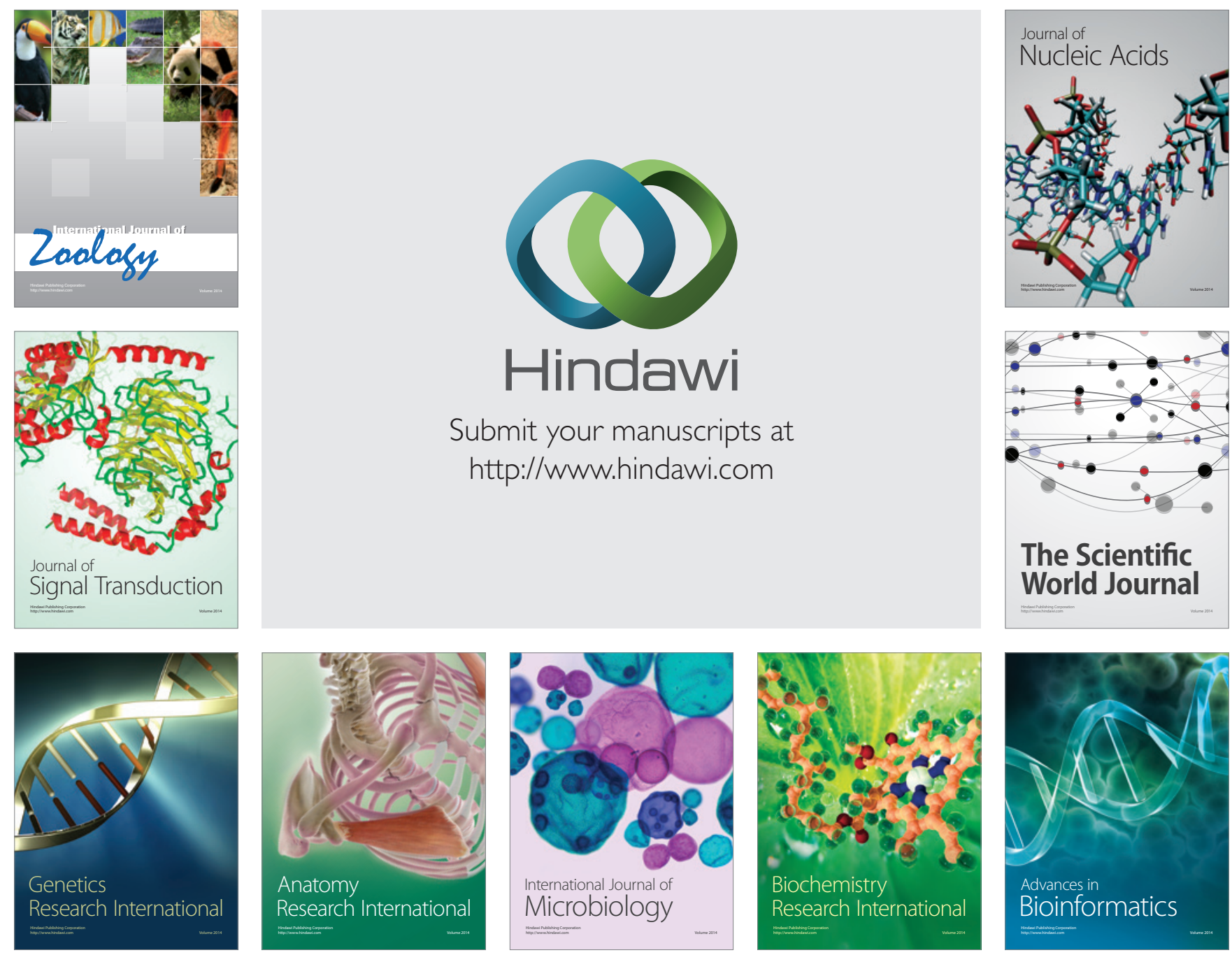

The Scientific World Journal
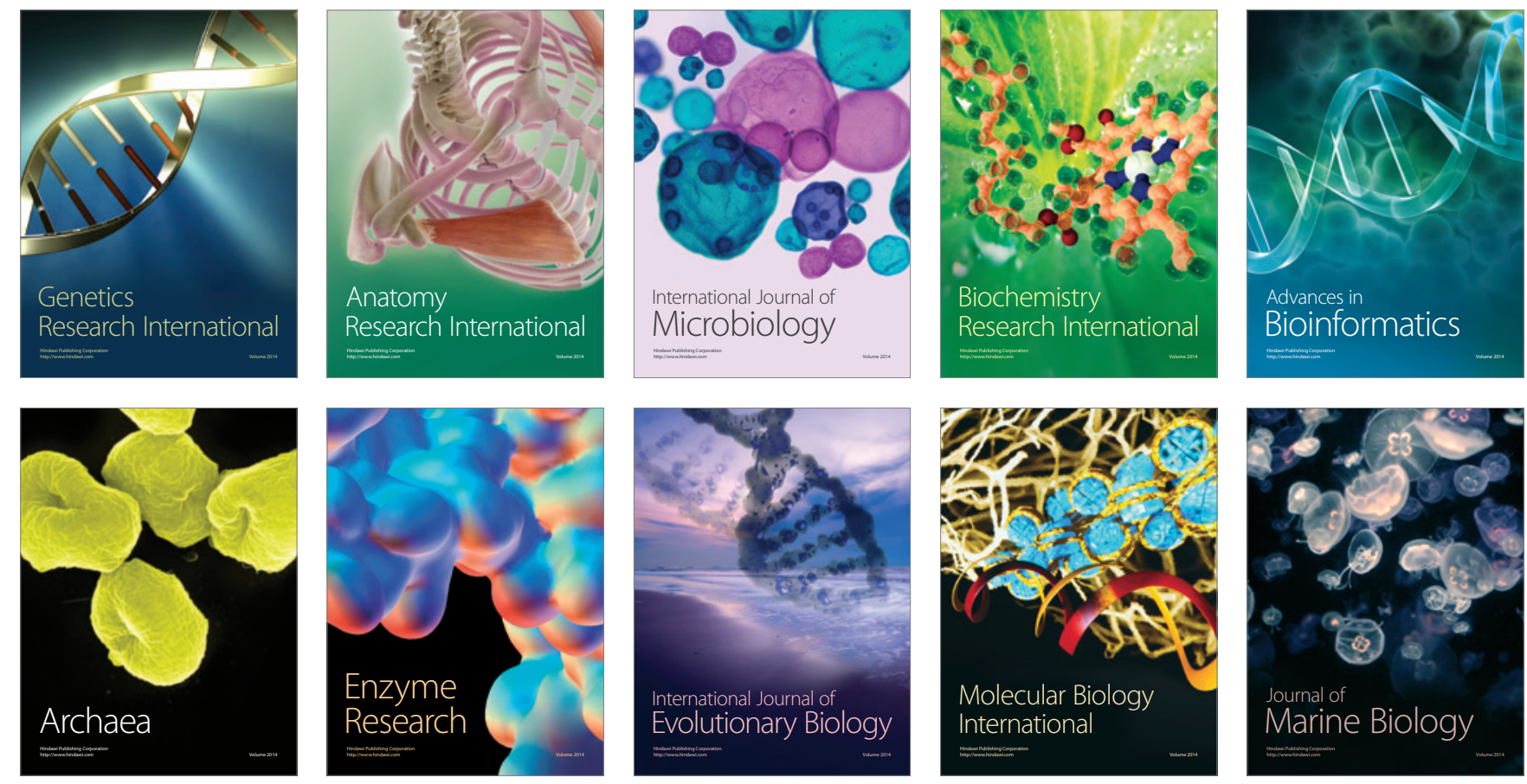